This item was submitted to Loughborough's Research Repository by the author.

Items in Figshare are protected by copyright, with all rights reserved, unless otherwise indicated.

\title{
Comparative analysis of conjugated alkynyl chromophore-triazacyclononane ligands for sensitized emission of europium and terbium
}

\section{PLEASE CITE THE PUBLISHED VERSION}

http://dx.doi.org/10.1002/chem.201402415

\section{PUBLISHER}

(c) Wiley-VCH Verlag GmbH \& Co.

\section{VERSION}

NA (Not Applicable or Unknown)

\section{PUBLISHER STATEMENT}

This work is made available according to the conditions of the Creative Commons Attribution-NonCommercialNoDerivatives 4.0 International (CC BY-NC-ND 4.0) licence. Full details of this licence are available at: https://creativecommons.org/licenses/by-nc-nd/4.0/

\section{LICENCE}

CC BY-NC-ND 4.0

\section{REPOSITORY RECORD}

Soulie, Marine, Frederik Latzko, Emmanuel Bourrier, Virginie Placide, Stephen Butler, Robert Pal, James W. Walton, et al.. 2014. "Comparative Analysis of Conjugated Alkynyl Chromophore-triazacyclononane Ligands for Sensitized Emission of Europium and Terbium”. Loughborough University. https://hdl.handle.net/2134/18776. 


\title{
Comparative analysis of conjugated alkynyl chromophore-triazacyclononane ligands for sensitized emission of europium and terbium.
}

Marine Soulié, ${ }^{[a]}$ Frédéric Latzko, ${ }^{[a]}$ Emmanuel Bourrier, ${ }^{[a]}$ Virginie Placide, ${ }^{[b]}$ Stephen J. Butler, ${ }^{[c]}$ Robert Pal, ${ }^{[c]}$ James W. Walton, ${ }^{[c]}$ Patrice L. Baldeck, ${ }^{[b, e]}$ Boris Le Guennic, ${ }^{[d]}$ Chantal Andraud, ${ }^{[b]}$ Jurriaan M. Zwier, ${ }^{[\mathrm{a}]}$ Laurent Lamarque ${ }^{\left[{ }^{[a]}, *\right.}$ David Parker ${ }^{[\mathrm{c}] *}$ and Olivier Maury ${ }^{[\mathrm{b}] *}$

[a] Cisbio Bioassays, Parc Marcel Boiteux, BP 84175, 30200 Codolet, France.

E-mail:llamarque@cisbio.com

[b] University of Lyon, ENS Lyon, CNRS - UMR 5182, 46 Allée d'Italie 69364 Lyon, France. E-mail : olivier.maury@ens-lyon.fr

[c] Department of Chemistry, Durham University, South Road, Durham, DH1 3LE, UK.

E-mail:david.parker@dur.ac.uk

[d] Institut des Sciences Chimiques de Rennes, UMR 6226 CNRS, Université de Rennes 1, 263 Avenue du Général Leclerc 35042 Rennes, France.

[e] Laboratoire de spectrométrie Physique Université Joseph Fourier, BP 87 F-38402 Saint Martin d'Hères, France.

\begin{abstract}
An extensive series of europium and terbium complexes is described based on the same functionalised tri-azacyclononane carboxylate or phosphinate macrocyclic ligand. The influence of the anionic group, i.e. carboxylate, methyl or phenyl phosphinate, on the photophysical properties is studied and rationalised on the basis of DFT calculated structures. The nature, number and position of aryl electron-donating or withdrawing substituents have been varied systematically within the same phenylethynyl scaffold in order to optimize the brightness of the related europium complexes and investigate their two-photon absorption properties. Finally, the europium complexes were examined in cell imaging applications, whilst selected terbium derivatives were studied as potential oxygen sensors.
\end{abstract}




\section{Introduction.}

Over the last two decades, various aspects of f-element spectroscopy have been extensively studied [1] and lanthanide coordination complexes in particular have found important applications in the biological sciences.[2] In this context, they have been used as luminescent probes for one or twophoton imaging, $[3,4]$ as responsive probes able to detect and quantify in vitro or in cellulo a biological activity or the presence of a given substrate $(\mathrm{pH}$, metal ions, bicarbonate, lactate, urate)[5] and as emissive bio-conjugated tags for time-resolved Förster resonance energy transfer assays.[6]

The f-block elements present intrinsic spectroscopic advantages for such applications. Their sharp emission bands and large pseudo-Stokes shifts, following indirect ligand excitation, facilitate selective detection in biological media even in a multiplexing experiment, and their long excited state lifetime enables time-resolved detection of the luminescence signal.[6c] These spectral and temporal resolutions result in a significant increase of the signal-to-noise ratio, a crucial issue for imaging purposes.[7]

All these favourable properties have triggered the design of numerous complexes that meet a stringent set of requirements: (i) the complexes must be strongly coordinated to minimize nonradiative losses and ensure their stability in biological medium, bearing in mind that coordinated water molecules are effective quenchers of the lanthanide excited state, (ii) they have to be sufficiently water soluble and (iii) they must possess optimal brightness $B(B=\varepsilon \Phi)$ for enhanced detection, ideally at an excitation wavelength above $330-350 \mathrm{~nm}$ to allow the use of glass microscopy objectives. The choice of the chelating ligand and of the organic chromophore antenna modifies these requirements [8] and has led to the design of several classes of compounds e.g. cryptates,[9] helicates,[10] polyaminocarboxylates or phosphinates [11] or macrocyclic derivatives, including those based on the well-known cyclen family.[12] In this context, taking advantage of the established stability of lanthanide complexes of triazacyclononane-tris-pyridine carboxylates [13 ] or (methyl/phenyl) phosphinates,[14] [Ln.Lc], [Ln.Lmp] or [Ln.Lpp], respectively (Figure 1), we recently reported ytterbium-based bio-probes for thick tissue imaging using near infra-red two-photon microscopy [15] and europium based bio-probes with exceptional brightness able to image cellular mitochondria and to act as a FRET donor ([Eu.Lc $\left.{ }^{a}\right]$, [Eu.Lmp $\left.{ }^{a}\right]$ or [Eu.Lpp $\left.{ }^{a}\right]$, Figure 1).[16] This exceptional brightness, about $25000 \mathrm{~mol} . \mathrm{L}^{-1} . \mathrm{cm}^{-1}$ upon excitation at $340 \mathrm{~nm}$, is about one order of magnitude higher than those already reported for europium complexes, and can be mainly explained by the optimization of the extinction coefficient of the complex using alkoxyphenylethynyl charge transfer antenna.[17] In addition, europium complexes of heptadentate ligands featuring identical antenna have been reported to present additional sensing properties, following displacement of the coordinated water molecule.[18]

The high potential of this series of complexes prompted us to gain further insight and understanding with respect to the influence of the nature of the antenna on their luminescence properties. Herein, we report the synthesis and spectroscopic properties of a complete series of europium and terbium complexes featuring various antennae, based on the same phenylethynyl scaffold. The nature, number and position of aryl electron-donating or withdrawing substituents has been varied systematically (Figure 1), and the photophysical properties of [Eu.Lc ${ }^{\mathrm{a}}$ ], [Eu.Lmp ${ }^{\mathrm{a}}$ ] and [Eu.Lpp ${ }^{\mathrm{a}}$ ] compared and discussed based on their DFT-calculated structures. Finally, the europium complexes were examined in cell imaging applications whilst selected terbium derivatives have been studied as potential oxygen sensors. 


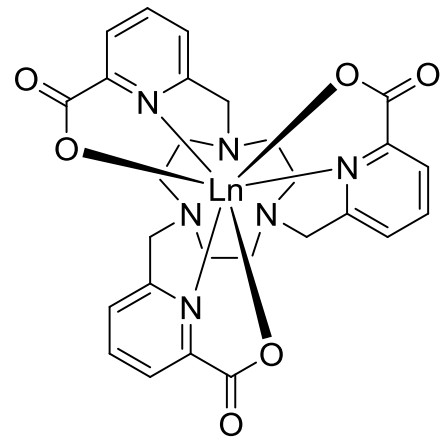

TACN pyridine-carboxylate series noted [Ln.Lc]

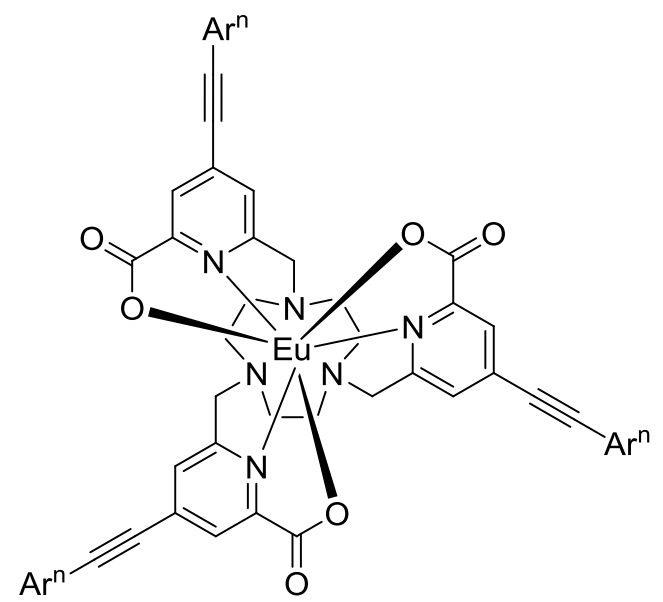

$\left[E u \cdot L c^{a-g}\right]$

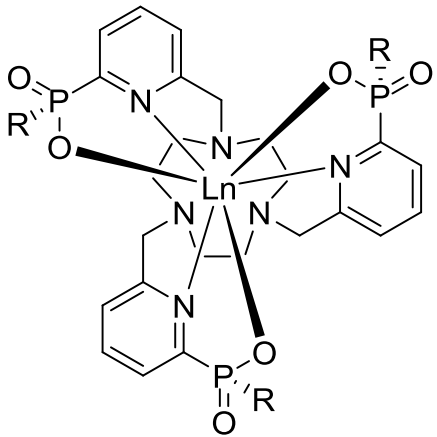

TACN pyridine- $R$-phosphinate series noted [Ln.Lpp] for $\mathrm{R}=\mathrm{Ph}$ and [Ln.Lmp] for $\mathrm{R}=\mathrm{Me}$

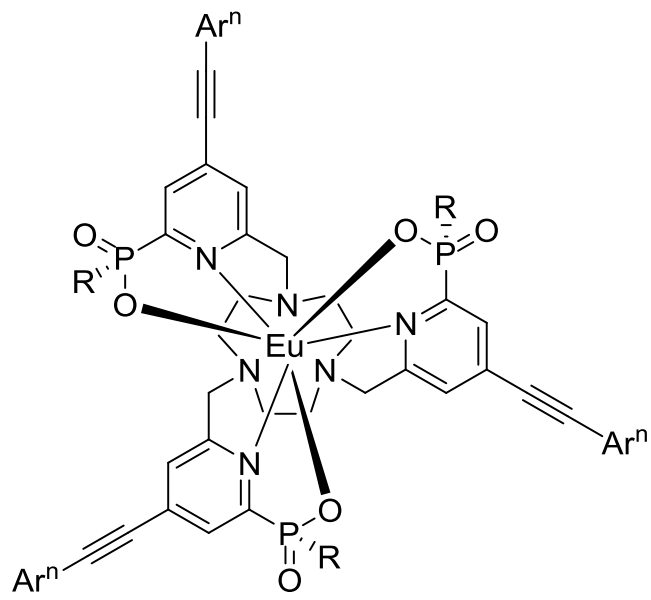

[Eu.Lpp $\left.{ }^{a j}\right]$ for $R=P h$

[Eu.Lmp $\left.{ }^{\text {a-f }}\right]$ for $\mathrm{R}=\mathrm{Me}$

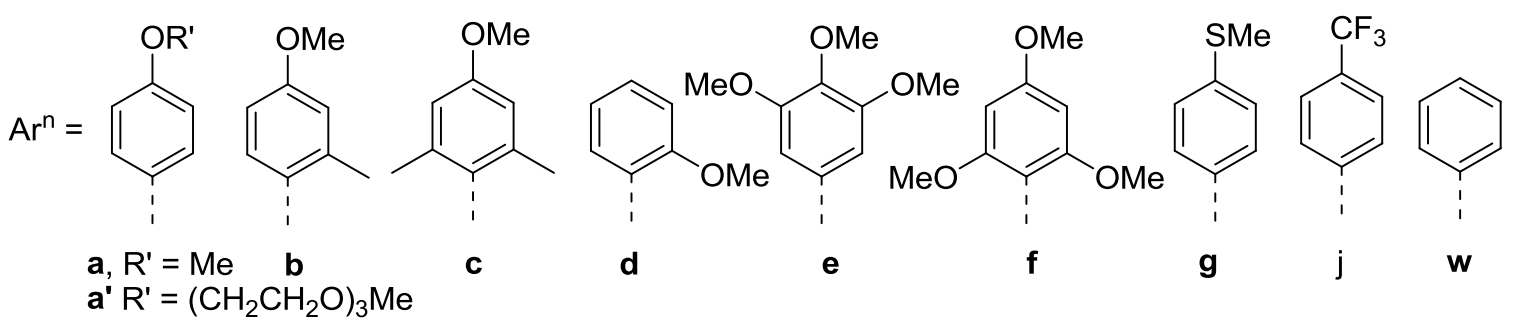

Figure 1. Structures of the complexes.

\section{Results and discussion}

Synthesis. The synthesis of the TACN pyridine-carboxylate series is depicted in Scheme 1 and starts from the commercially available free aryl-alkynes $\mathbf{1} \mathbf{a}, \mathbf{b}, \mathbf{d}(\mathrm{X}=\mathrm{H})$ or trimethylsilyl protected derivatives, 1e,g which were prepared according to literature procedures (see SI). Sonogashira palladium cross-coupling with the pyridine derivative $\mathbf{2} \mathbf{a}$ led to the chromophore scaffold in good yield. The chromophores $\mathbf{1} \mathbf{e , g}$ were obtained using the modified Sonogashira procedure by addition of tetrabutylammonium fluoride in the reaction mixture, which allows in situ deprotection of the trimethylsilyl group. Alternatively, we demonstrated that the trimethylsilyl alkyne moiety could be incorporated on the pyridine ring leading to $\mathbf{2 b}$ in $90 \%$ yield. However, due to the poor stability of the 
corresponding free alkyne $\mathbf{2 c}$, the desired compound was not obtained. We circumvented this issue by using the previous modified Sonogashira cross coupling reaction, leading to the chromophore $\mathbf{3 c}$.<smiles>CC(=O)c1cc(I)cc(CO)n1</smiles>

2a.

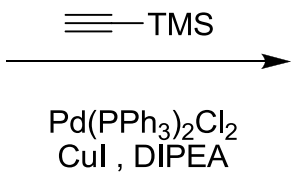
THF<smiles>CCC(C)(C)C#Cc1cc(CO)nc(C(=O)OC)c1</smiles>

2b. (90\%)

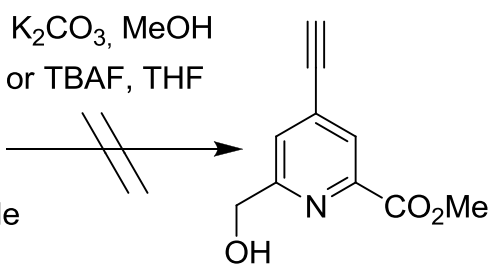

2c. (traces)

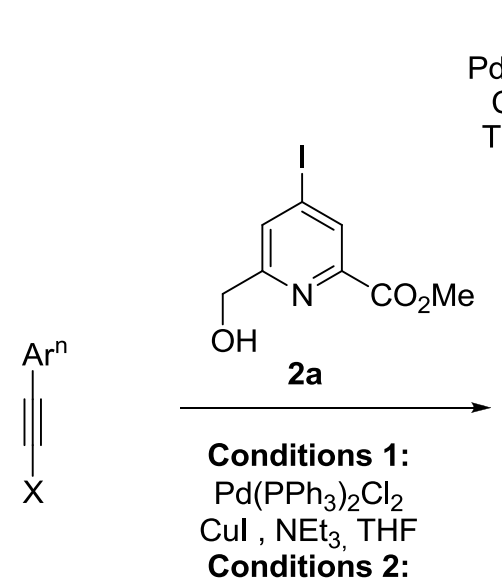
conditions $1+$ TBAF

1a. $\mathrm{X}=\mathrm{H}$ (Condit. 1)

1b. $X=H$ (Condit. 1)

1d. $X=H$ (Condit. 1)

1e. $X=$ TMS (Condit. 2)

1g. $X=$ TMS (Condit. 2$)$

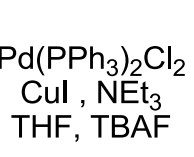

(O)<smiles>Cc1cc(O)cc(C)c1I</smiles>

1c. $(90 \%)$<smiles>CC(=O)c1cc(C#C[Al])cc(CO)n1</smiles>

3a. $(85 \%)$

3b. $(88 \%)$

3c. $(27 \%)$

3d. $(84 \%)$

3e. $(30 \%)$

3g. $(95 \%)$<smiles>COCc1cc(C#CC#[Al])cc(C(=O)OC)n1</smiles>

4a. $(90 \%)$
4b. $(34 \%)$
4c. $(50 \%)$
4d. $(80 \%)$
4e. $(7 \%)$
4g. $(36 \%)$

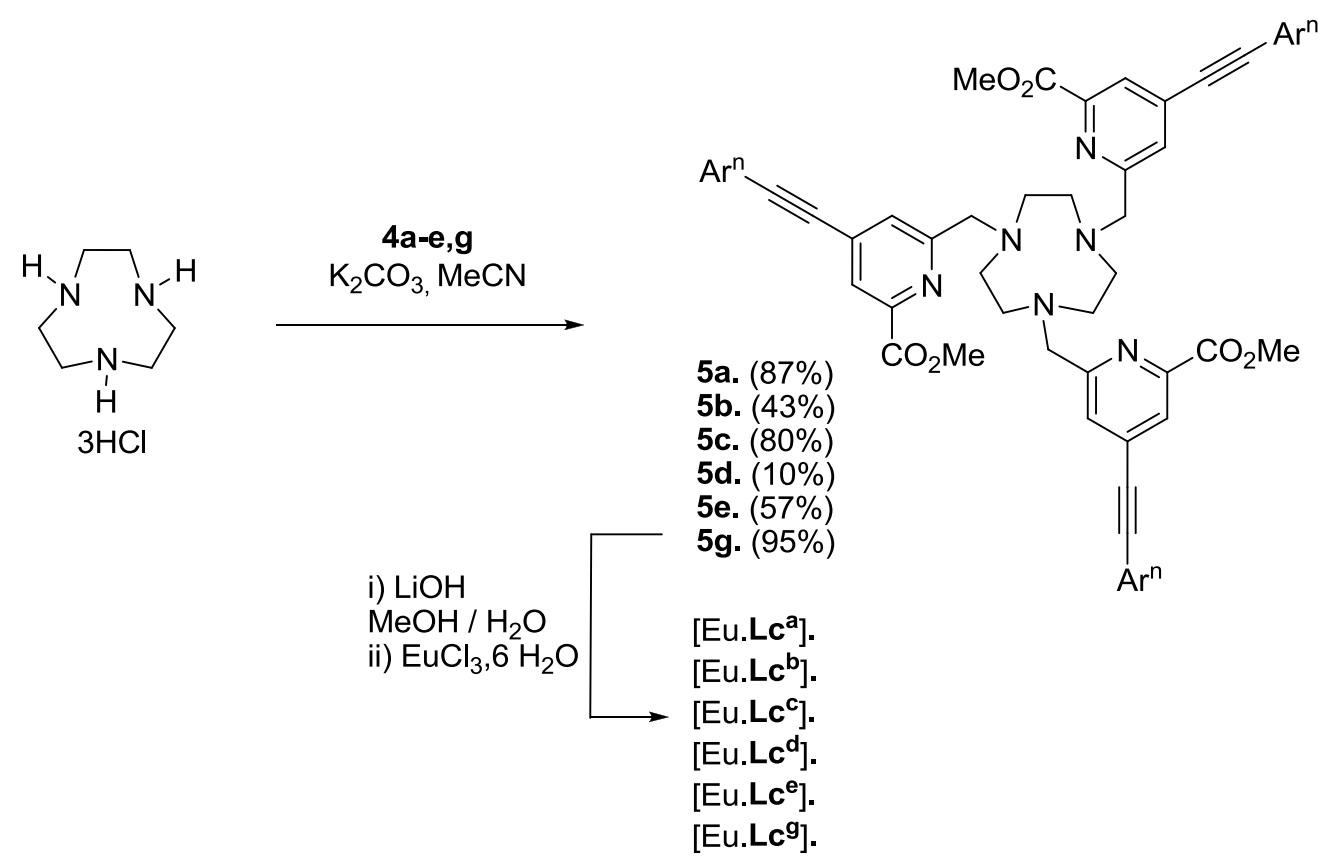

Scheme 1. Syntheses of the europium complex carboxylate series. 
The starting material 1c was readily available by alkylation of the corresponding iodo-phenol (see SI). Activation of the alcohol $\mathbf{3}$ was carried out using mesyl chloride and gave after purification on silica gel the corresponding mesylated compounds $4 \mathbf{a}-\mathbf{e}, \mathbf{g}$. Alkylation of TACN in the presence of potassium carbonate in acetonitrile gave rise to ligands $\mathbf{5 a - e , g}$ which were subsequently hydrolysed and the europium complexes were formed by addition of europium chloride hexahydrate. Each complex was isolated after purification by preparative HPLC and the structure was confirmed by HRMS.
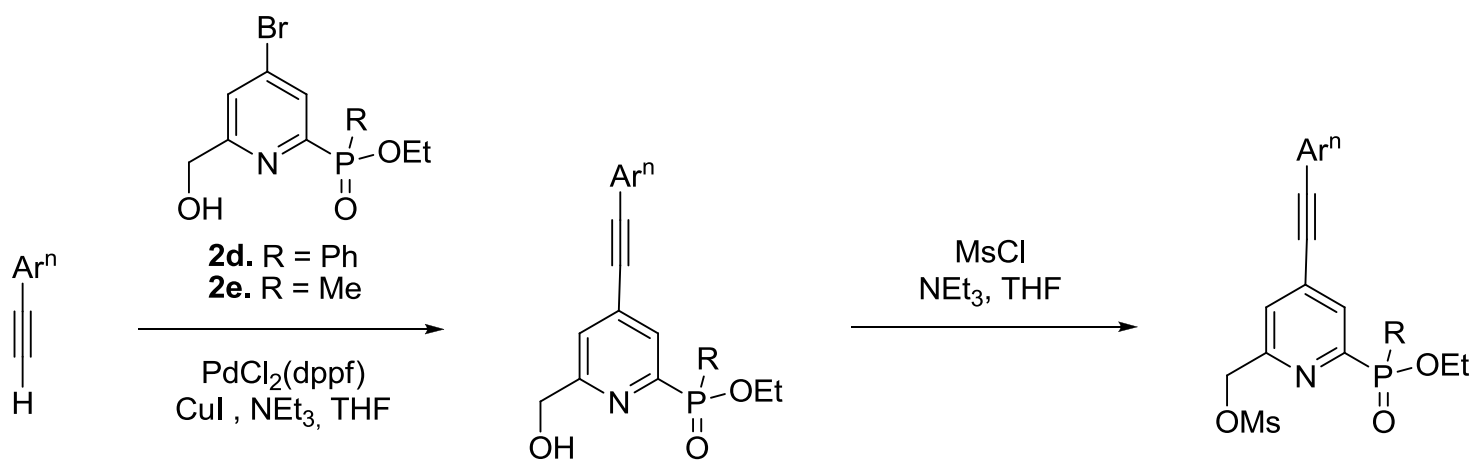

1b, 1f, 1j
6b. $R=M e(82 \%)$
6f. $R=\operatorname{Me}(76 \%)$
6j. $\mathrm{R}=\mathrm{Ph}(62 \%)$

7b. $R=$ Me (quant.)

7f. $R=M e$ (quant.)

7j. $\mathrm{R}=\mathrm{Ph}$ (quant.)

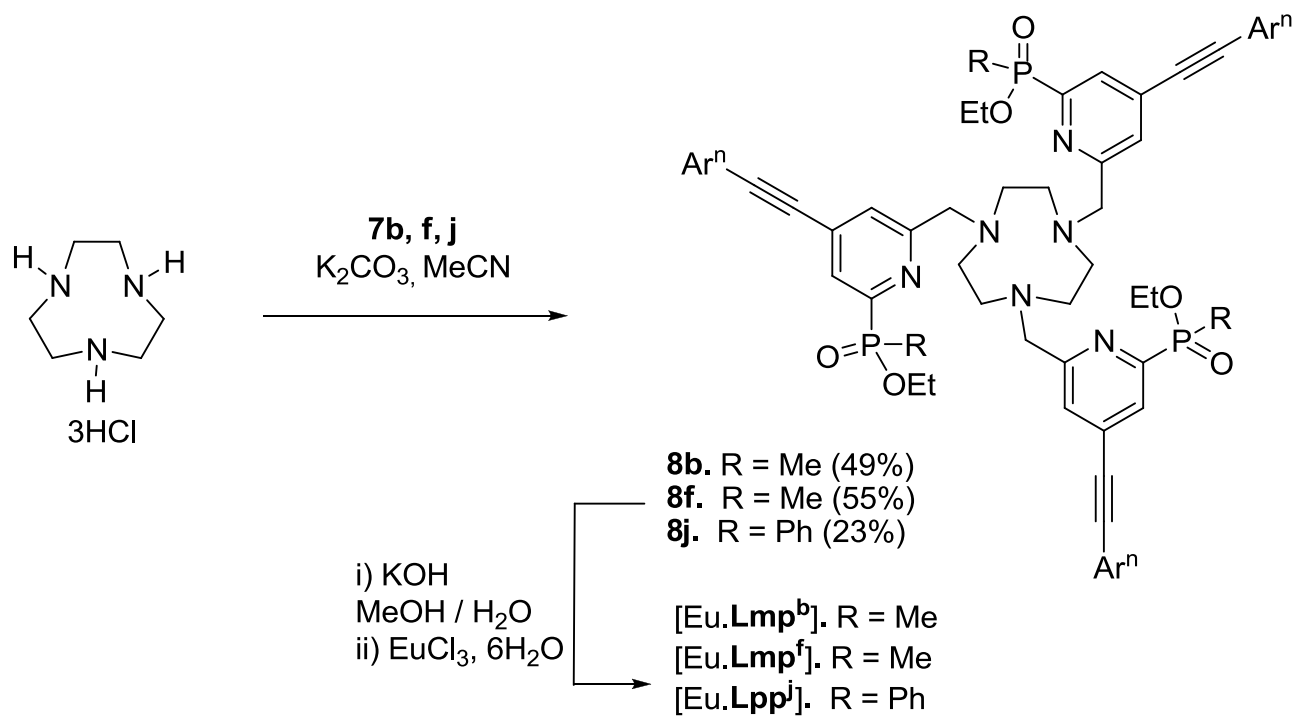

Scheme 2. Syntheses of the europium phosphinate complex series

Details of the syntheses of $\mathbf{L p p}^{\mathrm{a}}$ and $\mathbf{L p p}^{\mathbf{a}^{\prime}}$ have been reported earlier.[16] The synthesis of the ligands $\mathbf{L} \mathbf{m} \mathbf{p}^{\mathbf{b}}, \mathbf{L} \mathbf{m} \mathbf{p}^{\mathbf{f}}$ and $\mathbf{L} \mathbf{p} \mathbf{p}^{\mathbf{j}}$ (Scheme 2) involved preparation of the $p$-bromo pyridyl phosphinate intermediates $\mathbf{2 d , e}$, which were elaborated to the conjugated alkynyl chromophores $\mathbf{6 b}, \mathbf{f}, \mathbf{j}$ using a $\mathrm{Pd}$-catalyzed Sonogashira coupling reaction. Subsequent mesylation of the pyridyl alcohol and alkylation with triazacyclononane, followed by basic hydrolysis of the phosphinate ester groups provided the nonadentate ligands $\mathbf{L} \mathbf{m} \mathbf{p}^{\mathbf{b}}, \mathbf{L} \mathbf{L} \mathbf{p}^{\mathrm{f}}$ and $\mathbf{L} \mathbf{p} \mathbf{p}^{\mathrm{j}}$ in good yield, over three steps. 
Structural comparison between $\left[\mathrm{EuLc}^{\mathrm{a}}\right],\left[\mathrm{EuLpp}^{\mathrm{a}}\right],\left[\mathrm{EuLmp}^{\mathrm{a}}\right]$

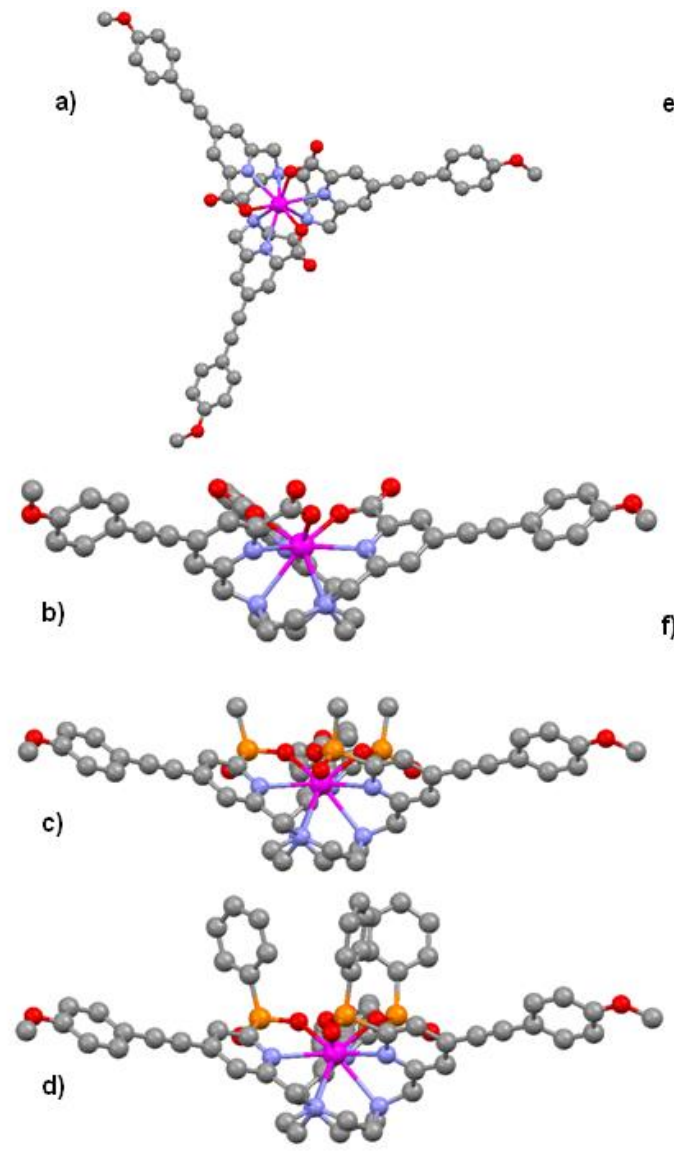

e)

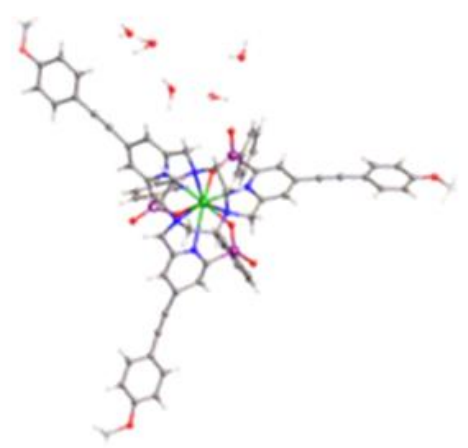

f)

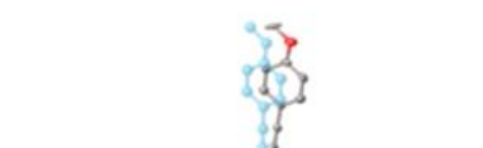

Figure 2. left: DFT-optimized structure of $\left[Y L^{a}\right],(a, b)\left[Y L^{2} p^{a}\right]$ (c) and $\left[Y L^{2} p^{a}\right](d)$ with the $C_{3}$ symmetry axis perpendicular (a) or parallel $(b, c, d)$ to the figure plane. Atom colors: $\mathrm{C}-$ gray, $\mathrm{N}-$ blue, $\mathrm{O}-$ red, $\mathrm{P}$ - orange, $\mathrm{Y}$ - magenta. Hydrogen atoms have been omitted for clarity; right: e) views of the $\mathrm{X}$-ray structure of [Eu.Lpp ${ }^{a}$ (CCDC 857545),[16a] showing the correspondence between X-ray (bold) and f) DFT (ghost) structures.

DFT geometry optimizations were performed in order to evaluate the influence of the nature of the chelating arm, i.e. carboxylate, methyl-phosphinate or phenyl phosphinate to the complex coordination sphere (see computational details in experimental section). Model complexes, [YLc ${ }^{\mathrm{a}}$ ], $\left[Y L^{2} p^{a}\right]$ and $\left[Y_{L p p}{ }^{a}\right]$ in which the paramagnetic $\mathrm{Eu}(\mathrm{III})$ ion was replaced by $\mathrm{Y}(\mathrm{III})$, were considered in order to simplify the calculations.[19] Each complex adopts a helical structure with overall $\mathrm{C}_{3}$ symmetry (Figure 2). The coordination polyhedron is a slightly distorted tri-capped trigonal prism, composed of three nitrogen atoms of the 1,4,7-triazacyclononane ring, three nitrogen atoms of the pyridine fragment $\left(\mathrm{N}_{\mathrm{py}}\right)$ and three oxygen atoms from either the carboxylate or phosphinate substituents. The calculated bond lengths and angles (Table 1) follow a similar trend to that observed in the X-ray structure of [Eu.Lpp $\left.{ }^{\mathrm{a}}\right][16 \mathrm{a}]$ or related unsubstituted complexes.[13,14] The tetrahedral geometry around the phosphorus atom in complexes [Y.Lpp $\left.{ }^{a}\right]$ and [Y.Lmp $\left.{ }^{a}\right]$ imposes a smaller $\left(C_{p y}, P, O\right)$ angle of ca $101^{\circ}$ compared to the $112^{\circ}$ of the $\left(C_{p y}, C, O\right)$ angle of $\left[Y . L c^{a}\right]$ and consequently the five membered chelate ring $\left(\mathrm{Y}, \mathrm{N}_{\mathrm{py}}, \mathrm{C}_{\mathrm{py}}, \mathrm{P}, \mathrm{O}\right)$ is more constrained than the analogous carboxylate chelate $\left(\mathrm{Y}, \mathrm{N}_{\mathrm{py}}, \mathrm{C}_{\mathrm{py}}, \mathrm{C}, \mathrm{O}\right)$. These observations explain why the $\mathrm{Y}-\mathrm{N}_{\mathrm{py}}$ distances are longer and why the central metal ion is more deeply encaged in the phosphinate derivatives compared to the 
carboxylate ones, as illustrated by the variation of the distance $d$ between the $\mathrm{Y}$ atom and the plane composed by the three nitrogen atoms of the TACN ring (Table 1). In addition, it is important to note that in the case of the phosphinate derivates, the methyl or phenyl substituents of the phosphorus atom point along the $\mathrm{C}_{3}$ axis and provide significant steric protection of the upper side of the complexes. Moreover, in the X-ray structure of [Eu.Lpp $\left.{ }^{a}\right]$, there is only one classical intermolecular $\pi-\pi$ interaction found in the lattice, involving the phenyl phosphinate rings and not the alkynyl moieties. The centroid-centroid distance was $4.07 \AA$, with the two phenyl rings shifted by $1.90 \AA$ from perfect stacking.

Table 1. Salient optimised DFT distances $(\AA)$ and angles $\left({ }^{\circ}\right)$ for the series of $Y(I I I)$ model complexes.

\begin{tabular}{|c|c|c|c|}
\hline & {$\left[\mathrm{Y} . \mathrm{Lc}^{\mathrm{a}}\right]$} & [Y.Lmp $\left.{ }^{\mathrm{a}}\right]$ & [Y.Lpp $\left.{ }^{\text {a }}\right]$ \\
\hline $\mathrm{Y}-\mathrm{N}$ & $2.829 / 2.830 / 2.831$ & $2.787 / 2.787 / 2.787$ & $2.768 / 2.768 / 2.769$ \\
\hline $\mathrm{Y}-\mathrm{N}_{\mathrm{py}}$ & $2.563 / 2.563 / 2.564$ & $2.703 / 2.700 / 2.703$ & $2.676 / 2.676 / 2.676$ \\
\hline $\mathrm{Y}-\mathrm{O}$ & $2.246 / 2.247 / 2.247$ & $2.214 / 2.214 / 2.215$ & $2.213 / 2.214 / 2.213$ \\
\hline$d$ & 2.250 & 2.190 & 2.170 \\
\hline $\mathrm{N}-\mathrm{Y}-\mathrm{N}$ & $63.4 / 63.4 / 63.3$ & $64.7 / 64.7 / 64.7$ & $65.0 / 65.0 / 65.0$ \\
\hline$N_{p y}-Y-N_{p y}$ & 119.8/119.8/119.6 & 119.7/119.7/119.7 & $119.8 / 119.8 / 119.8$ \\
\hline O-Y-O & $94.5 / 94.3 / 94.3$ & 91.4/91.5/91.5 & $89.8 / 89.8 / 89.8$ \\
\hline $\mathrm{N}-\mathrm{Y}-\mathrm{O}^{\mathrm{a}}$ & 120.0/119.9/120.1 & $122.3 / 122.3 / 122.3$ & $123.6 / 123.6 / 123.6$ \\
\hline
\end{tabular}

${ }^{a}$ Intra-ligand angle.

\section{Photophysical properties of Europium complexes.}

Comparison between $L c, \operatorname{Lmp}$ and $\mathbf{L p p}$ ligands. The study of the photophysical properties of the complexes was performed in diluted methanol solution or in water and representative data are reported in Table 2. The comparison of the absorption and emission spectra of [EuLc ${ }^{\mathrm{a}}$ ], [EuLmp $\mathrm{p}^{\mathrm{a}}$ ], and [EuLpp ${ }^{\mathrm{a}}$ ] featuring identical antenna but different chelating groups is shown in Figure 3 . In their absorption spectra, every complex possesses a broad structureless transition, assigned to an intraligand charge transfer transition (ICT), from the methoxy-phenyl electron-donating group(s) to the pyridine electron-withdrawing fragment. Interestingly, the [EuLc $\left.{ }^{\mathrm{a}}\right]$ complex absorption is slightly redshifted compared to the phosphinate analogues, in terms of both the maximal absorption wavelength $\left(\Delta \lambda^{\max }=8 \mathrm{~nm}\right)$ and the red tail of the absorption band $\left(\Delta \lambda_{\text {cut-off }}=20 \mathrm{~nm}\right)$. This bathochromic shift can be explained by the shorter $\mathrm{Ln}-\mathrm{N}_{\mathrm{py}}$ distance observed for the carboxylate compound: a shorter distance leads to stronger coordination of the metal centre whose Lewis acidity enhances the accepting character of the pyridine fragment. 


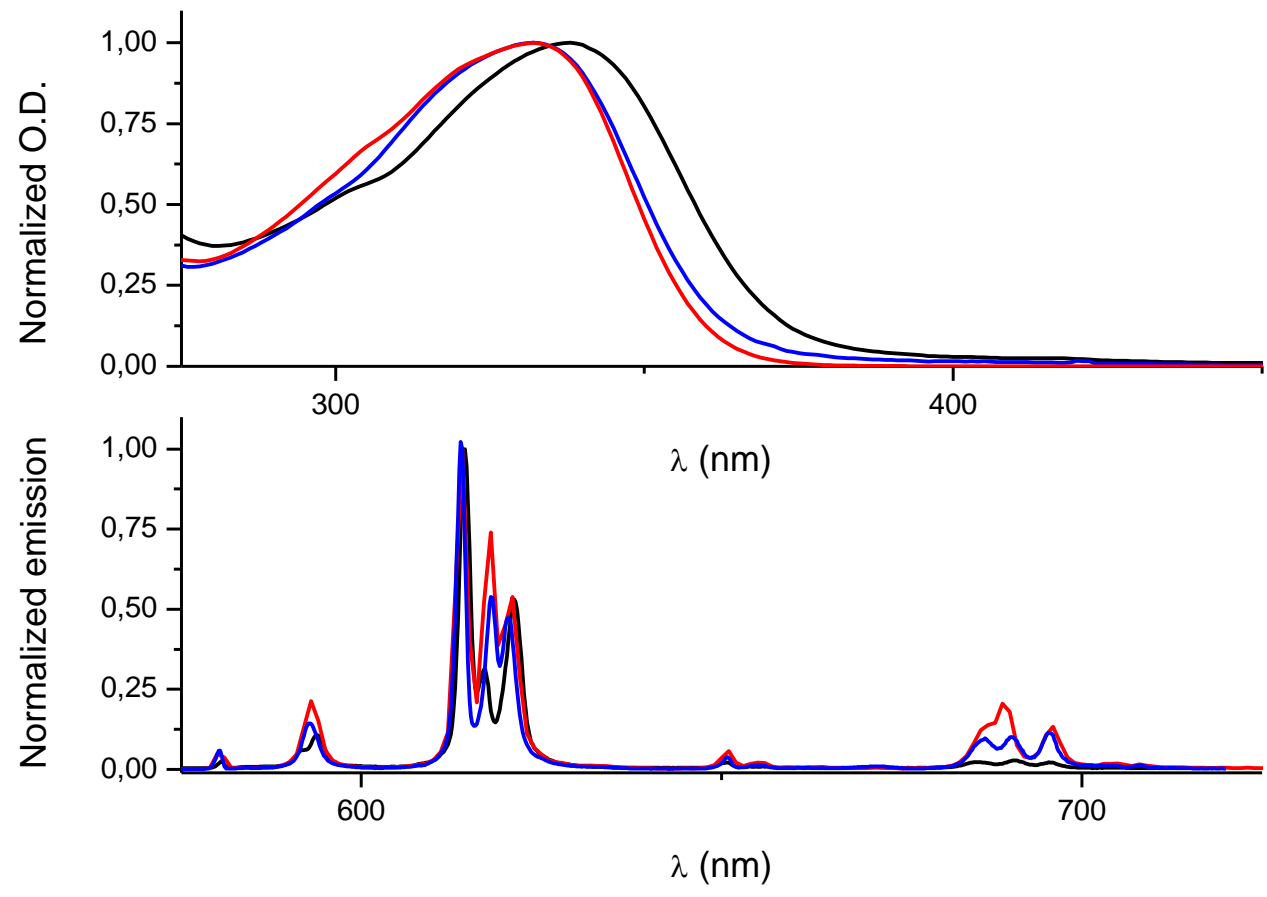

Figure 3. Comparison of the absorption (up) and emission (bottom) spectra of [EuLc ${ }^{\mathrm{a}}$ ] (black), [EuLmp ${ }^{\mathrm{a}}$ ] (blue), [EuLpp ${ }^{\mathrm{a}}$ ] (red) in methanol at room temperature.

The europium emission spectral profiles are very similar for each complex (Figure 3), with a hypersensitive $\Delta=2$ transition around $610-620 \mathrm{~nm}$, as expected for three-fold symmetric compounds incorporating polarisable donor groups. A small increase in the intensity of the $\Delta=4$ transition around $680-700 \mathrm{~nm}$ is observed for [EuLmp ${ }^{\mathrm{a}}$ ], and [EuLpp ${ }^{\mathrm{a}}$ ] compared to [EuLc ${ }^{\mathrm{a}}$ ], which may be tentatively associated with an increasing distortion from the ideal $C_{3}$ symmetry, in the case of the more bulky phosphinate derivatives. The three complexes present remarkable quantum yield efficiency in $\mathrm{MeOH}$ of $42,43,52 \%$ for [EuLc ${ }^{\mathrm{a}}$ ], [EuLmp ${ }^{\mathrm{a}}$ ] and [EuLpp ${ }^{\mathrm{a}}$ ] respectively (Table 2). In addition, in water the quantum yield of [EuLmp $\left.{ }^{\mathrm{a}}\right]$ is almost conserved (39\%) whereas it drops to $25 \%$ for $\left[E_{L u c}{ }^{a^{\prime}}\right]$, the water-soluble analogue of [EuLc $\left.{ }^{a}\right]$. Such behaviour is in agreement with the increased steric protection afforded by the methyl or phenyl substituents at phosphorus (Figure 2).

In order to get deeper insight into the influence of the nature of the coordinating function, the relevant radiative and non-radiative parameters were deduced from experimental data (spectra, quantum yields and lifetimes). Using the approach initially proposed by Werts, Verhoeven[20] and Beeby[21], the overall europium quantum yield of luminescence $\left(\phi_{\mathrm{Eu}}\right)$ is defined as the product of the efficiency of the sensitization (eq. $1, \eta_{\text {sens }}$, i.e. here the fraction of energy transferred from the donor state to the Eu(III) accepting levels) and the quantum efficiency of the metal-centred luminescence upon direct excitation into the $f$-levels $\left(\eta_{\mathrm{Eu}}\right)$ :

$$
\phi_{\mathrm{Eu}}=\eta_{\text {sens }} \eta_{\mathrm{Eu}}
$$

In this equation, $\eta_{\mathrm{Eu}}=\tau_{o b s} / \tau_{\mathrm{r}}$ where $\tau_{o b s}$ represents the experimental luminescence lifetime of the complex and $\tau_{r}$, the pure radiative lifetime, calculated from:

$$
k_{\mathrm{r}}=1 / \tau_{\mathrm{r}}=A(0,1)\left[I_{\mathrm{tot}} /(1(0,1)]\right.
$$


The constant $A(0,1)$ is the spontaneous emission probability of the ${ }^{5} D_{0} \rightarrow^{7} F_{1}$ transition, equal to $32 \mathrm{~s}^{-1}$ in methanol and $I_{\text {tot }} / I(0,1)$ is the ratio of the total integrated emission intensity to the intensity of the ${ }^{5} \mathrm{D}_{0} \rightarrow{ }^{7} \mathrm{~F}_{1}$ transition. Finally, $\Sigma k_{\mathrm{nr}}$ can be deduced knowing $k_{\mathrm{r}}$ and $\tau_{o b s}$, from the relationship:

$$
\Sigma k_{\mathrm{nr}}=1 / \tau_{\text {obs }}-1 / \tau_{\mathrm{r}} .
$$

This procedure was used for $\left[E u L c c^{a}\right],\left[E u L m p^{a}\right]$, and $\left[E u L p p^{a}\right]$ in methanol and the data are summarized in Table 2. It is clear that the increases of the quantum yield and experimental lifetime along the series $\left[\mathrm{EuLc}^{\mathrm{a}}\right]<\left[\mathrm{EuLmp}^{\mathrm{a}}\right]<\left[\mathrm{EuLpp}^{\mathrm{a}}\right]$ is directly connected to the strong decrease of the nonradiative constant from 642 to $396 \mathrm{~s}^{-1}$. These results clearly indicate that the increased steric protection afforded by the phosphinate substituent ( $\mathrm{Me}<\mathrm{Ph}$ ) contributes strongly to the rigidification of the complex structure, thereby reducing non-radiative de-excitation pathways.[14b]

Table 2. Calculated values of $\tau_{\mathrm{r}}, k_{\mathrm{r}}, \Sigma k_{\mathrm{nr}}$ for [EuLc ${ }^{\mathrm{a}}$ ], [EuLmp ${ }^{\mathrm{a}}$ ], [EuLpp ${ }^{\mathrm{a}}$ ] in methanol using the room temperature experimentally determined quantities $\tau_{\text {obs }}$ and $\left[I(0,1) / I_{\text {tot }}\right]$.

\begin{tabular}{llllll}
\hline Solvent & $\mathrm{I}(0,1) / \mathrm{I}_{\text {tot }}$ & $\tau_{\text {obs }}{ }^{\mathrm{b}} / \mathrm{ms}$ & $\tau_{\mathrm{r}} / \mathrm{ms}$ & $k_{\mathrm{r}} / \mathrm{s}^{-1}$ & $\sum k_{\mathrm{nr}} / \mathrm{s}^{-1}$ \\
\hline$\left[\mathrm{EuLc}^{\mathrm{a}}\right]$ & 0.087 & 0.99 & 2.72 & 368 & 642 \\
{$\left[\right.$ EuLmp $\left.^{\mathrm{a}}\right]$} & 0.079 & 1.18 & 2.47 & 405 & 443 \\
{$\left[\right.$ EuLpp $\left.^{\mathrm{a}}\right]$} & 0.086 & 1.30 & 2.68 & 473 & 396 \\
\hline
\end{tabular}

Influence of the alkynyl substitution. The influence of the aromatic substitution on the photophysical properties (absorption and emission) of the related europium (III) complexes was thoroughly studied. Table 3 compiles the spectroscopic data of compounds [EuLc $\left.{ }^{\mathrm{a}-\mathrm{g}}\right]$ alongside data for the unsubstituted compound $\left[\mathrm{EuLC}^{\mathrm{w}}\right]$ for comparison. The absorption spectrum of [EuLc $\left.{ }^{\mathrm{w}}\right]$ presents a structured transition with a maximum at $315 \mathrm{~nm}\left(\lambda_{\text {cut-off }}=335 \mathrm{~nm}\right)$ characteristic of a $\pi-\pi^{*}$ transition associated with a local excited state ( $\left.{ }^{1} \mathrm{LE}\right)$ (Figure 4).[22] As expected, the substitution of the aromatic moiety by electro-donating groups, e.g. OMe, SMe in compounds [EuLc $\left.{ }^{\mathrm{a}-\mathrm{g}}\right]$ induces a profound modification of the absorption spectra with the appearance of a broad structureless transition assigned, by comparison with analogous ligands, [9c, 17] to an intra-ligand charge transfer transition. These ICT transitions are bathochromically shifted and the magnitude of the red-shift $\left(\Delta^{a-g}=\lambda\left(\left[\right.\right.\right.$ EuLc $\left.\left.{ }^{a-g}\right]\right)-$ $\lambda\left(\left[\mathrm{EuLc}^{\mathrm{w}}\right]\right)$ is correlated to the strength of the donating groups. As a consequence of the stronger donor character of the SMe group compared to OMe, $\Delta^{\mathrm{g}}=34 \mathrm{~nm}$ is higher than $\Delta^{\mathrm{a}, \mathrm{d}}=19 \mathrm{~nm}$ exhibiting one methoxy substituent in para or ortho position, respectively. Introduction of additional methoxy groups in non-conjugated meta position does not induce any significant additional bathochromic shift $\left(\Delta^{\mathrm{e}}=21 \mathrm{~nm}\right)$. On the contrary, introduction of one or two weak electron donating methyl groups in the ortho position induces an additional red-shift of 30 and $36 \mathrm{~nm}$ for [EuLc ${ }^{\mathrm{b}}$ ] and $\left[\mathrm{EuLc}^{\mathrm{c}}\right]$, respectively. Finally, introduction of three methoxy groups in conjugated ortho, ortho', para positions in [EuLmp $\left.{ }^{f}\right]$ results in the strongest bathochromic shift of the ICT transition, with a maximal absorption wavelength at $360 \mathrm{~nm}$ and a $\lambda_{\text {cut-off }}$ value of $c a .410 \mathrm{~nm}$. It is therefore possible to finetune the maximum absorption wavelength and the cut-off wavelength in the spectral range of interest centered around $337 \mathrm{~nm}$, by varying the aromatic substitution. It is worth noting that this ICT transition is very intense, with an extinction coefficient of around $60000 \mathrm{~L}$. mol ${ }^{-1} . \mathrm{cm}^{-1}$ which is of prime importance in terms of brightness optimization. All compounds except [EuLc ${ }^{\mathrm{e}}$ ] are strongly emissive and exhibit the classical Eu(III) emission profile upon irradiation in the ICT transition. In each case, no residual ligand-centred emission was observed indicating that the energy transfer to the lanthanide ion is almost quantitative. The quantum yields in methanol are good to excellent, the 
highest value $(55 \%)$ being obtained for $\left[\mathrm{EuLc}^{\mathrm{b}}\right]$ and $\left[\mathrm{EuLmp}^{\mathrm{f}}\right]$ derivatives and are supported by long luminescence lifetime around $1 \mathrm{~ms}$. The photophysical properties of all complexes have not been evaluated in water due to their limited solubility except in the case of [EuLmp $\left.{ }^{\mathrm{a}}\right]$. The quantum yield (39\%) and lifetime $(1.01 \mathrm{~ms})$ in water are slightly lower than in methanol but remain significant indicating the good aqueous stability of this complex. Combined with the above-mentioned strong absorption, this family of complexes exhibits very high brightness around $337 \mathrm{~nm}$, which makes them very attractive candidates for bio-imaging or fluoroimunoassay applications.

Table 3. Spectroscopic properties of the complexes measured at room temperature in $\mathrm{MeOH}$.

\begin{tabular}{|c|c|c|c|c|c|}
\hline Complexes & $\begin{array}{l}\lambda_{\max } \\
(\mathrm{nm})\end{array}$ & $\begin{array}{l}\varepsilon \\
\left(\mathrm{mM}^{-1} \mathrm{~cm}^{-1}\right)\end{array}$ & $\begin{array}{l}\phi^{\mathrm{a}, \mathrm{b}} \\
(\%)\end{array}$ & $\begin{array}{l}\tau \\
(\mathrm{ms})\end{array}$ & $\begin{array}{l}\sigma_{\mathrm{TPA}}^{\mathrm{b}} \\
(\text { at } 700 \mathrm{~nm})\end{array}$ \\
\hline$\left[\mathrm{EuLc}^{\mathrm{a}}\right]$ & 339 & 58,000 & 42 & 0.99 & 46 \\
\hline$\left[\mathrm{EuLc}^{\mathrm{b}}\right]$ & 345 & 60,000 & 55 & 0.97 & \\
\hline$\left[E u L c c^{c}\right]$ & 351 & 60,000 & 45 & 0.90 & \\
\hline$\left[\right.$ EuLc $\left.^{d}\right]$ & 339 & 60,000 & 41 & 1.01 & 30 \\
\hline$\left[\mathrm{EuLc}^{\mathrm{e}}\right]$ & 341 & 60,000 & 8 & 0.49 & 36 \\
\hline$\left[E u L c^{\mathrm{g}}\right]$ & 349 & 60,000 & 32 & 0.85 & - \\
\hline$\left[\mathrm{EuLc}^{\mathrm{w}}\right]^{\mathrm{c}}$ & $315^{d}$ & $48,400^{d}$ & $22^{d}$ & $0.85^{d}$ & \\
\hline$\left[\right.$ EuLpp $\left.^{\mathrm{a}}\right]$ & 332 & 58,000 & 52 & 1.30 & 26 \\
\hline$\left[E u L m p^{a}\right]$ & 331 & 58,000 & 43 & 1.18 & - \\
\hline [EuLmp $\left.{ }^{\mathrm{b}}\right]$ & 340 & 62,000 & 54 & 1.14 & \\
\hline [EuLmp ${ }^{f}$ ] & 360 & 57,000 & 55 & $1.05^{c}$ & \\
\hline
\end{tabular}

(a) Quinine sulfate as standard excitation at $335 \mathrm{~nm}$, errors on quantum yield or lifetime are +/-15\%; (b) errors are +/-20\%; (c) data recorded in water according to ref $13 a$.

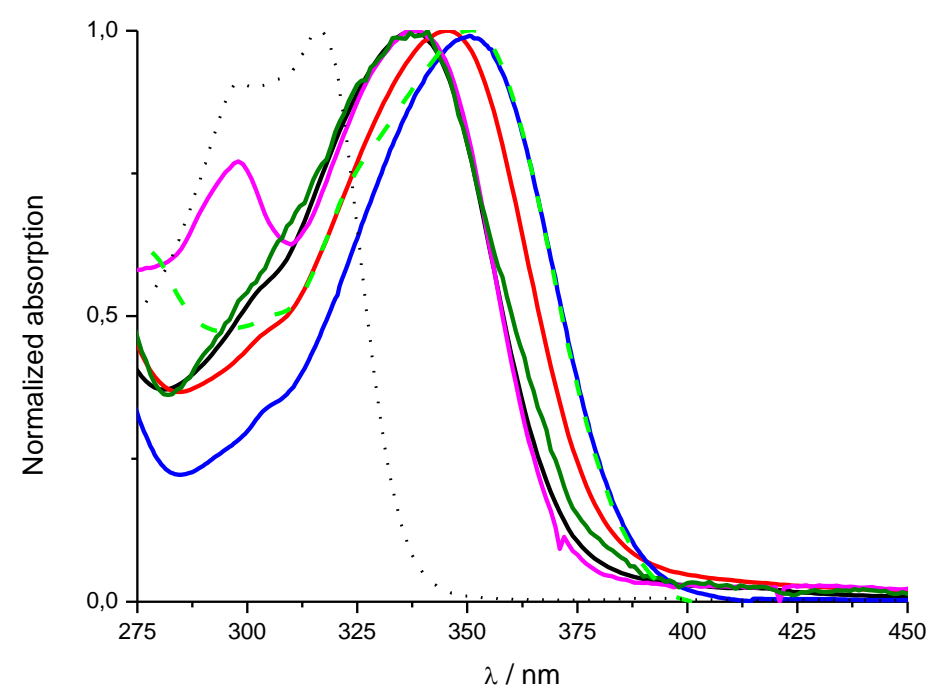

Figure 4. Normalized absorption spectra of complexes [EuLc ${ }^{\mathrm{a}-\mathrm{w}}$ ] in diluted methanol solution (black $\operatorname{dot}\left[\mathrm{EuLc}^{\mathrm{w}}\right]$; black [EuLc $\left.{ }^{\mathrm{a}}\right]$; red [EuLc $\left.{ }^{\mathrm{b}}\right]$; blue [EuLc $\left.{ }^{\mathrm{c}}\right]$; pink [EuLc $\left.{ }^{\mathrm{d}}\right]$; olive [EuLc $\left.{ }^{\mathrm{e}}\right]$; dashed green [EuLc $\left.\mathbf{c}^{\mathrm{g}}\right]$ ) 
Sensitisation process. In related tris-dipicolinate complexes, europium sensitisation has been shown to occur by an efficient intramolecular energy transfer process involving a relaxed and fairly broad ICT excited state and not via a localised ligand triplet state, notably for strong electro-donating moieties.[17b] In the case of weak donor groups like alkyl or alkoxy, the ICT state lies at higher energy and consequently a contribution of the classical triplet mediated sensitisation process remains possible.[17a] The complexes [GdLmp $\left.{ }^{f}\right]$ and $\left[G d L p p^{a^{\prime}}\right]$ were prepared and investigated in order to study the influence of the chelating groups on the sensitisation process (Figure 5). At low temperature, both complexes exhibit a broad structureless emission, characteristic of an ICT state, at 415 and $375 \mathrm{~nm}$ for [GdLmp ${ }^{\mathrm{f}}$ ] and [GdLpp ${ }^{\mathrm{a}^{\prime}}$ ] respectively, together with weaker structured emission from the ligand centred triplet state (e.g. vibrational overtones at 490 and $470 \mathrm{~nm}$ ). At room temperature, only a broad structureless ICT emission is observed around $460 \mathrm{~nm}$. This variable temperature measurement clearly indicates the presence of a triplet excited state at approximately the same energy as the ICT state. Consequently the two sensitization pathways, namely the triplet state mediated one or the direct ICT process can be simultaneously involved in the europium luminescence sensitisation process.

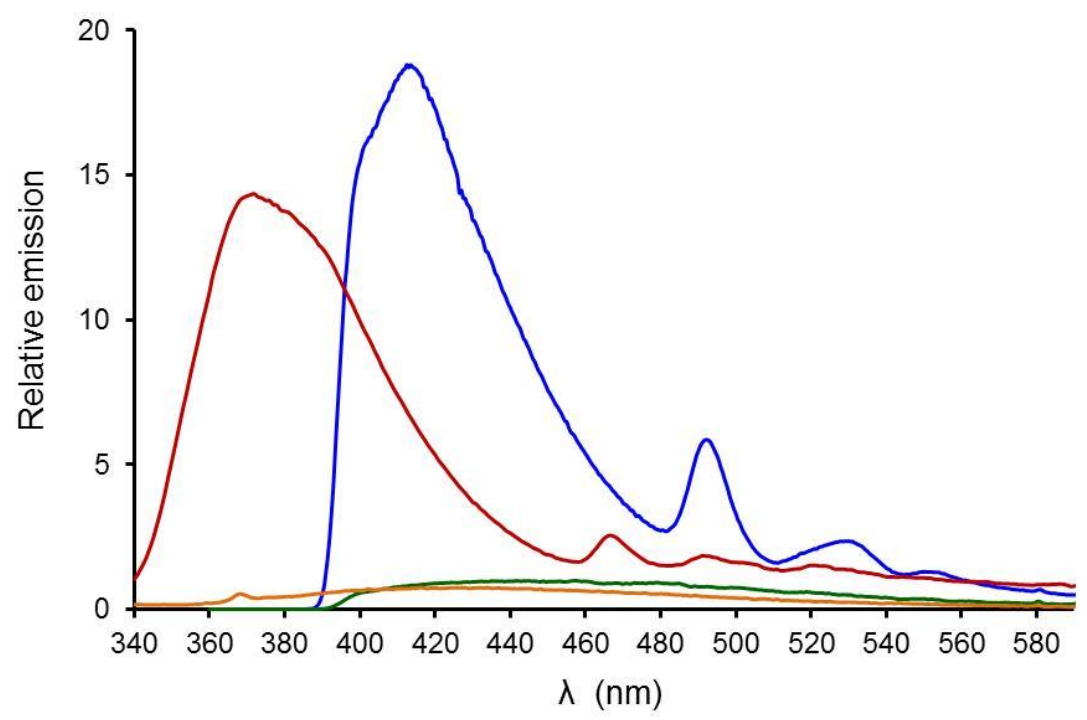

Figure 5. Emission spectra of [Gd.Lmp ${ }^{\mathrm{f}}$ ( $\lambda_{\mathrm{exc}}=355 \mathrm{~nm}$ ) measured at $77 \mathrm{~K}$ (blue) and $295 \mathrm{~K}$ (green), as well as [Gd.Lpp ${ }^{\mathrm{a}^{\prime}}$ ] $\left(\lambda_{\text {exc }} 330 \mathrm{~nm}\right.$ ) at $77 \mathrm{~K}$ (red) and $295 \mathrm{~K}$ (orange). Recorded in an EPA glass (ether/isopentane/ethanol, $5: 5: 2 \mathrm{v} / \mathrm{v} / \mathrm{v}$ ).

The parent $\mathrm{Eu}(\mathrm{III})$ complexes did not show significant spectral variation with solvent polarity, except for the Eu complex of the 2,4,6-tri-methoxyphenyl triphosphinate ligand, Lmp ${ }^{\mathbf{f}}$. In this particular case, the emission intensity increased in less polar solvents (Table 4 and Figure $\mathrm{S} 1$ in ESI). In solvents with a normalised polarity parameter, $\mathrm{E}_{\mathrm{T}}(30)$ of $<0.8$ (Reichardt scale: e.g. $\mathrm{MeOH}, \mathrm{EtOH}, \mathrm{PrOH}, \mathrm{MeCN}, \mathrm{DMF}$ ) the lifetime increased slightly from 1.06 in $\mathrm{MeOH}$ to 1.18 in ${ }^{\mathrm{i}} \mathrm{PrOH}$. Based on the assumption that the extinction coefficients of the lowest energy ICT band do not vary by more than $10 \%$ in the examined solvents, the overall emission quantum yield varied from $55 \%$ in $\mathrm{MeOH}$ to $78 \%$ in 'PrOH. However, in water the lifetime was $0.70 \mathrm{~ms}$, the quantum yield dropped to $5 \%$, and the primary absorption band of the ICT state broadened, extending beyond $405 \mathrm{~nm}$.

The variation of the emission intensity with $T$ (range 180 to 295K) was examined in EPA and the change of intensity and lifetime with $\mathrm{pO}_{2}$ (range 0.4 to $160 \mathrm{mmHg}$ ) was examined in water at ambient temperature. The temperature variation was characterised by an increase of overall emission intensity of a factor of 2 between 295 and 230K followed by a drop in intensity at much lower temperatures (Figure S2 in ESI). The emission intensity varied non-linearly (Figure S3 in ESI) 
with $\mathrm{pO}_{2}$ at values below $35 \mathrm{mmHg}$, (viz. $160 \mathrm{mmHg}$ is atmospheric pressure), with a 2.6 fold increase in intensity at $0.4 \mathrm{mmHg} v$ ambient pressure.

Taken together, the absorption, solvent, $T$ and oxygen-dependent changes observed for [EuLmp ${ }^{f}$ ] support a sensitisation mechanism involving a 'solvent-relaxed' ICT excited state, which may transfer its energy to the $E{ }^{5} D_{1}$ and/or ${ }^{5} D_{0}$ excited states. The energy of this ICT excited state is lowered in the most polar solvent water, such that thermally activated ( $T$-dependent) back energy transfer may occur, extending the lifetime of the ICT state and thereby increasing its sensitivity to non-radiative deactivation.

Table 4. Variation of spectral behaviour with solvent polarity for [EuLmp ${ }^{\mathrm{f}}$ ]

\begin{tabular}{lllll}
\hline Solvent & $\mathrm{E}_{\mathrm{T}}{ }^{\mathrm{N}}$ & $\lambda_{\max }(\mathrm{nm})$ & $\tau(\mathrm{ms})$ & $I_{\text {rel }}(\%)^{\mathrm{a}}$ \\
\hline water & 1.00 & 360 & 0.72 & 10 \\
$\mathrm{MeOH}$ & 0.76 & 360 & 1.06 & 55 \\
EtOH & 0.65 & 360 & 1.15 & 71 \\
${ }^{\text {'PrOH }}$ & 0.55 & 360 & 1.18 & 78 \\
$\mathrm{MeCN}$ & 0.46 & 350 & 1.17 & 81 \\
DMF & 0.40 & 350 & 1.17 & 75
\end{tabular}

(a) relative emission intensities were estimated based on the assumption that the extinction coefficient of [Eu.Lmp ${ }^{f}$ ] is the same in each solvent, and are calibrated with the quantum yield in $\mathrm{MeOH}$; prior work has shown that for water and methanol, the ICT extinction coefficients of the lowest energy band are very similar, within an error of $\pm 10 \%$.

Nonlinear optical properties. The presence of the extended $\pi$-conjugated antenna ligand prompted a determination of the two-photon absorption cross-section of selected complexes. To that end, twophoton excited fluorescence (TPEF) measurements, based on the calibration of the two-photon excitation spectra in the 700-900 $\mathrm{nm}$ range have been performed in diluted methanol using coumarin-307 as external reference (see experimental section for details). The two-photon absorption spectra are reported in Figure 6 and it clearly appears that the maximal absorption wavelength is located out of our laser excitation range and that only the red tail of the two-photon absorption spectrum can be measured. At $700 \mathrm{~nm}$, all compounds present rather modest twophoton absorption cross sections of between $25-50 \mathrm{GM}$; these values lie in the range of recently described complexes with similar antenna groups.[4a, 9c, 17, 23] Such properties render this family of complexes suitable for biphotonic microscopy imaging applications. 


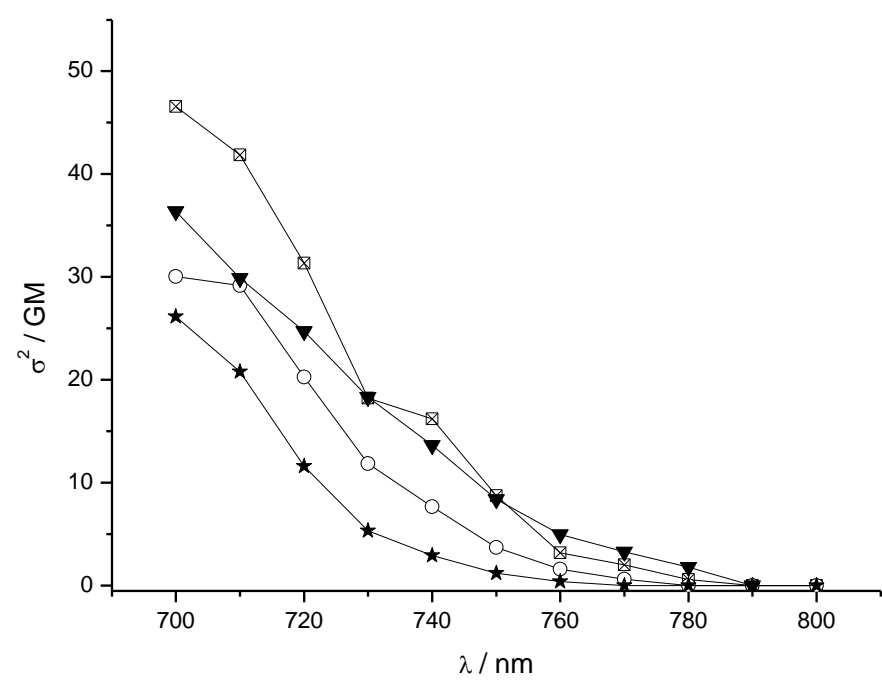

Figure 6. Two-photon absorption measured by TPEF in methanol of [EuLc ${ }^{\mathrm{a}}$ ] (open square), [EuLc ${ }^{d}$ ] (open circle), [EuLc ${ }^{\mathrm{e}}$ (black triangle), and [EuLpp ${ }^{\mathrm{a}}$ (black star).

Bioimaging application: mitochondrial staining in different cell types. In a preliminary communication, we had indicated that certain Eu complexes in this family exhibit cell uptake, with a tendency to highlight the mitochondrial network. [14a] Indeed, it has been possible to obtain both single $\left(\lambda_{\text {exc }} 355,365 \mathrm{~nm}\right)$ and two-photon $\left(\lambda_{\text {exc }} 710-730 \mathrm{~nm}\right)$ microscopy images with several of the complexes described herein.[24] The single photon images are representative and will be described here. It is worth noting that the high optical brightness of the probes allows live cell imaging at high resolution (Figure 7). Thus, using mouse skin fibroblasts (NIH-3T3) stained with [EuLmp ${ }^{\mathrm{b}}$ ] or [EuLmp ${ }^{\mathrm{f}}$ ], their high brightness permits use of a new experimental technique that can be termed 'phasemodulated nanoscopy' to reduce lateral resolution further ( $d_{\text {lat }}=125 \mathrm{~nm}$ at $\left(\lambda_{\mathrm{exc}} 355 \mathrm{~nm}, 1.4 \mathrm{NA}\right)$ ).[16] This is revealed in the definition of the mitochondrial network to $\sim 80 \mathrm{~nm}$ resolution.

The complex [EuLmp ${ }^{f}$ ] absorbs even more strongly at $355 \mathrm{~nm}$ and has been examined as well in human liver adenocarcinoma cells (HepG2), revealing the mitochondrial distribution better than the common stain, MitoTracker Green (MTG). These liver cells form defined local foci instead of a well dispersed monolayer. Therefore, we set out to conduct a simple comparison of the tissue penetration of [EuLmp ${ }^{f}$ ] versus Mitotracker Green. This Eu complex appears to permeate the foci more deeply, allowing more effective visualization of the taller axial sections of these densely packed cells. Following uptake via macropinocytosis [25] the complex must be shuttled to the mitochondria, crossing the outer membrane and localizing in the inter membrane space. It does not seem likely that these high molecular weight $(\mathrm{MW}>500)$ probes are able to cross the inner mitochondrial membrane. Such behaviour may then explain their low mitochondrial toxicity, as revealed by $\mathrm{IC}_{50}$ values of $>100 \mu \mathrm{M}(24 \mathrm{~h})$, using the MTT assay. The MitoTracker stains are based upon substituted benzylic chlorides that irreversibly alkylate Cys residues in various mitochondrial proteins (e.g. heat shock protein-60, VDAC-1, aldolase-A) [26] and can also attack mitochondrial DNA, via alkylation at guanine $\mathrm{N}-7$. These reactions result in irreversible perturbation of normal organelle function, so that these organic dyes are only able to penetrate and stain the outer layers of the foci, subsequently forming a perturbed cell barrier. These shallow superficial stained cell layers appear not to allow penetration and transportation of the organic dye deeper into the tissue. Also, it can be clearly seen 
in the sets of images (Figure 7) in HepG2 cells, that the Eu compound does not stain the lipid droplets that appear as very bright spots in the images using the organic dye.

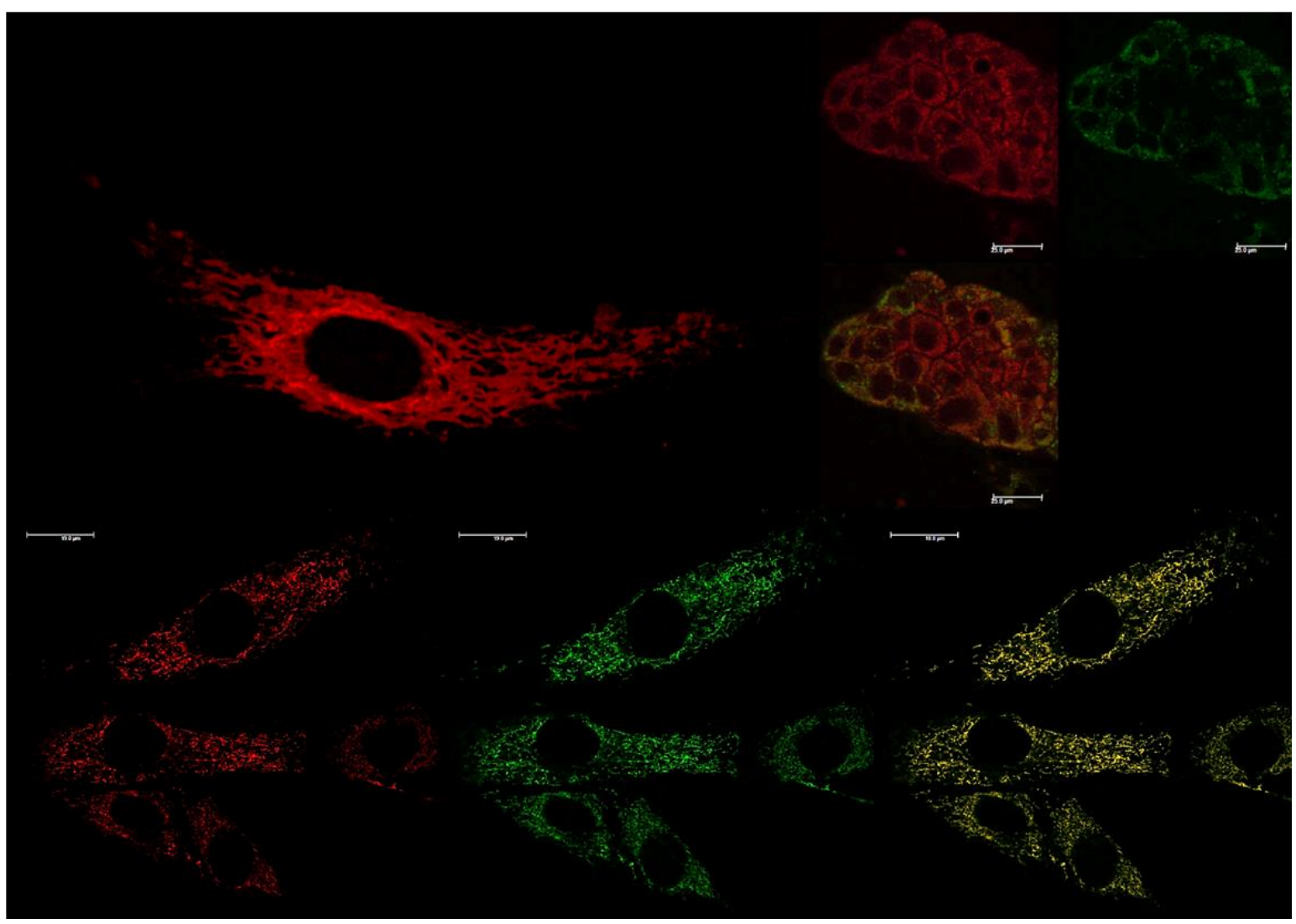

Figure 7. Upper Left $\mathrm{NIH} 3 \mathrm{~T} 3$ cells stained with $\left[\mathrm{EuLmp}^{\mathrm{b}}\right]$, showing the very clear mitochondrial network at high resolution (using an in-house Phase Modulation Nanoscope: 2048 × 2048 pixels, voxel size $60 \times 60 \times 780 \mathrm{~nm}$ )); upper right [EuLmp ${ }^{\mathrm{f}}$ ] in HepG2 cells (which tend to clump together, forming local foci during culturing) in red, showing higher definition and resolution compared to images with MitoTracker Green, and a co-localised image; lower: [EuLmp ${ }^{f}$ ] (30 $\mu \mathrm{M}$ loading concentration) in NIH $3 \mathrm{~T} 3$ cells (left, $2 \mathrm{~h}$ loading; $30 \mathrm{~min}$ for MTG, centre), showing the co-localisation (right) with MTG images, RGB merge (P> 0.9); (1024 x 1024 pixels, voxel size $120 \times 120 \times 780 \mathrm{~nm}, 100$ $\mathrm{Hz}$ scan 4 averaged).

Photophysical properties of terbium complexes. The effect of changing the nature of the parasubstituent on the phenyl ring was considered in attempting to make this ligand suitable for terbium sensitisation. This strategy requires both the raising of the energy of the ligand singlet excited state and/or the relative energy of the ICT and ligand centred triplet states. Earlier work [27] has shown that very little terbium emission was observed under ambient conditions for complexes of the ligands with chromophores possessing electron releasing substituents, e.g. $\mathbf{L c}^{\mathbf{a}}$ and $\mathbf{L} \mathbf{\text { Lp }}{ }^{\mathrm{a}}$. Even in deoxygenated solution, $\left[\mathrm{TbLpp}^{\mathrm{a}}\right]$ gave only very weak emission $\left(\phi_{\mathrm{em}}(\mathrm{MeOH})=0.3 \%\right.$ at $295 \mathrm{~K}$, Figure S4in ESI). Sensitisation is much less likely to occur with the terbium analogues, as the $\mathrm{Tb}$ ion requires that the broad ICT state lies well above the terbium ${ }^{5} \mathrm{D}_{4}$ accepting state at $20,400 \mathrm{~cm}^{-1}$. Indeed, sensitisation of terbium in the near UV by an antenna normally requires that there be a significant energy gap between the energy of the excited state of the sensitising moiety and the accepting Tb ${ }^{5} \mathrm{D}_{4}$ level.[8] In this situation, the rate of thermally activated back energy transfer is minimised when the energy gap is $>8 \mathrm{kT}$, i.e. $1640 \mathrm{~cm}^{-1}$ at $298 \mathrm{~K}$. In an effort to identify a system that may allow Tb sensitisation with reduced or zero oxygen sensitivity, the excited state energies of a set of 
chromophores 9b-e with electron poor substituents were measured (Scheme 3, Table 5 and Figure 8).

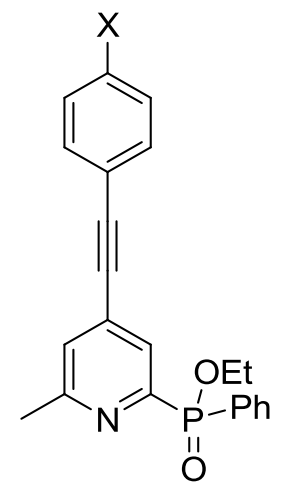

9b. $X=\mathrm{C}(\mathrm{O}) \mathrm{OEt}$

9c. $X=\mathrm{C}(\mathrm{O}) \mathrm{NEt}_{2}$

9d. $X=C N$

9e. $\mathrm{X}=\mathrm{CF}_{3}$

Scheme 3. Structure of the phenylphosphinate model chromophores $9 \mathbf{b}$-e featuring electron withdrawing substituents.

Table 5. Selected photophysical properties for phenylphosphinate-based pyridyl-alkynyl chromophores $9 \mathrm{~b}-\mathrm{e}$ (295K, $\mathrm{MeOH}$, or as stated)

\begin{tabular}{lllll}
\hline compound & Substituent $\mathrm{X}$ & $\lambda_{\max }(\mathrm{nm})$ & $\varepsilon\left(\mathrm{mM}^{-1} \mathrm{~cm}^{-1}\right)^{\mathrm{a}}$ & $E_{\mathrm{T}}\left(\mathrm{cm}^{-1}\right)^{\mathrm{b}}$ \\
\hline [GdLpp $\left.{ }^{\mathrm{a}^{\prime}}\right]$ & $\left(\mathrm{OCH}_{2} \mathrm{CH}_{2}\right)_{3} \mathrm{OMe}$ & 320 & 25,000 & 21,300 \\
9b & $\mathrm{CO}_{2} \mathrm{CH}_{2} \mathrm{CH}_{3}$ & 314 & 31,800 & 21,200 \\
9c & $\mathrm{CON}\left(\mathrm{CH}_{2} \mathrm{CH}_{3}\right)_{2}$ & 310 & 34,600 & 21,600 \\
9d & $\mathrm{CN}$ & 312 & 33,500 & 21,000 \\
9e & $\mathrm{CF}_{3}$ & 298 & 15,000 & 21,800
\end{tabular}

(a) errors are $\pm 5 \%$; (b) triplet energies were measured at $77 \mathrm{~K}$ in an EPA glass (ether/isopentane/ ethanol, $5: 5: 2 \mathrm{v} / \mathrm{v} / \mathrm{v}$ ).

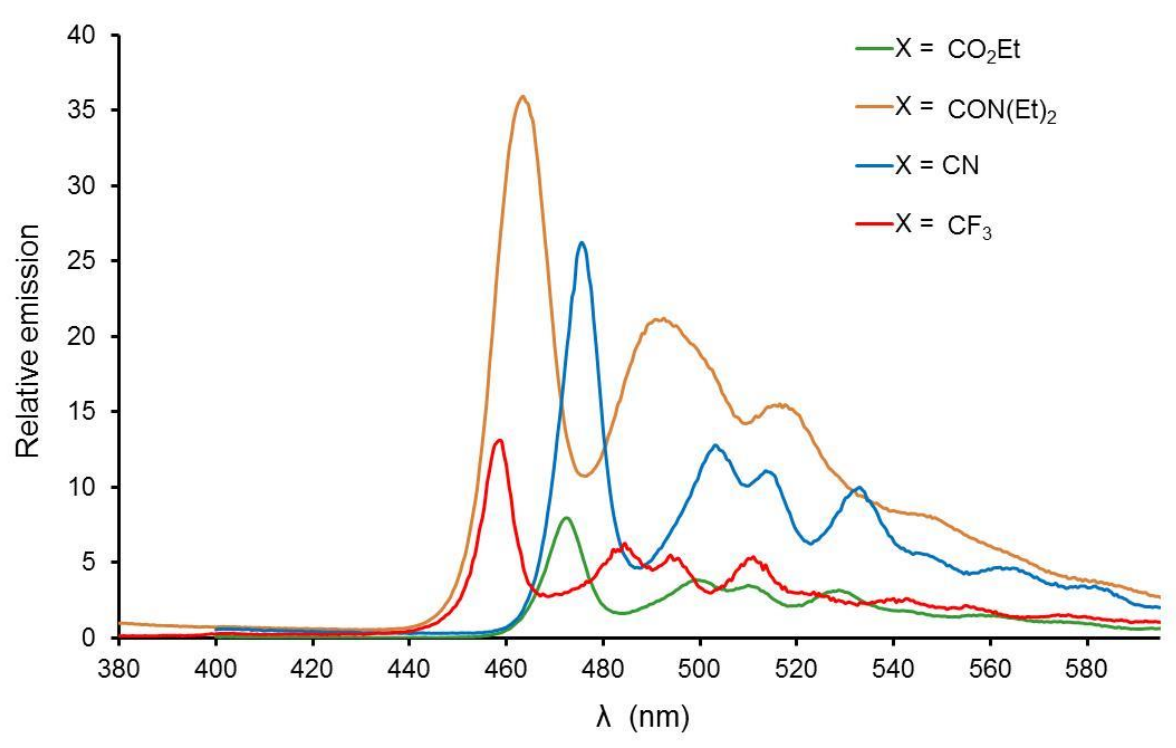

Figure 8. Phosphorescence emission spectra of a series of phenylphosphinate model chromophores 9b-e measured in an EPA glass (ether/isopentane/ethanol, $5: 5: 2 \mathrm{v} / \mathrm{v} / \mathrm{v}$ ) at $295 \mathrm{~K}$. 
Oxygen sensing with Eu/Tb mixtures. The $p$ - $\mathrm{CF}_{3}$-substituted chromophore possesses the highest triplet energy of this series. Indeed, the low $T$ spectra show that the triplet excited state is of lower energy than the ICT state in this case. Accordingly, the corresponding ligand $\mathbf{L p p} \mathbf{p}^{\mathbf{j}}$ was prepared and the spectral properties of the $\mathrm{Tb}$ and $\mathrm{Eu}(\mathrm{III})$ complexes analysed in the presence of varying partial pressures of oxygen. The Eu complex showed no change in intensity as $\mathrm{pO}_{2}$ was varied, whereas the $\mathrm{Tb}$ analogue exhibited a strong dependence on dissolved oxygen concentration (Figure 9). The Tb dependence on oxygen partial pressure was assessed over the range 0.03 to $159 \mathrm{mmHg}$, and showed a linear dependence, associated with a Stern-Volmer quenching constant, $\mathrm{K}_{\mathrm{sv}}{ }^{-1}$ of $60 \mathrm{~mm} \mathrm{Hg}$. The differing behaviour of the Eu and Tb complexes allows oxygen concentrations to be measured using mixtures (1:10 ratio) of the Eu/Tb complexes, by examining the ratio of the green Tb emission at 545 $\mathrm{nm}$ to the red Eu emission at $620 \mathrm{~nm}$ (Figures 10). Such behaviour has previously been observed for related systems [27] where reversible energy transfer re-populates the sensitizer triplet excited state and renders it sensitive to collisional quenching by triplet oxygen.

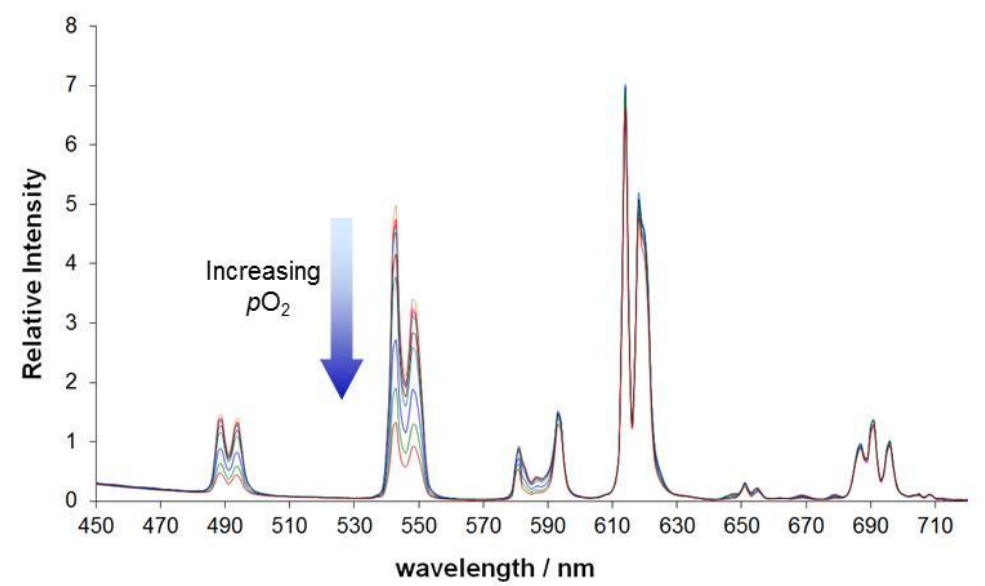

Figure 9. Emission spectra of the mixture of complexes [LnLpp $\left.{ }^{\mathrm{j}}\right]\left(\mathrm{Eu} / \mathrm{Tb}\right.$ ratio $\left.=1: 10, \lambda_{\text {exc }} 308 \mathrm{~nm}\right)$ showing the change in the $\Delta J=-1 \mathrm{~Tb}$ emission band intensity (centred at $545 \mathrm{~nm}$ ) compared to the $\Delta J$ $=2 \mathrm{Eu}$ band (centred at $615 \mathrm{~nm}$ ), as the atmospheric pressure (and hence the concentration of dissolved molecular oxygen) was varied from $2-760 \mathrm{mmHg}$.

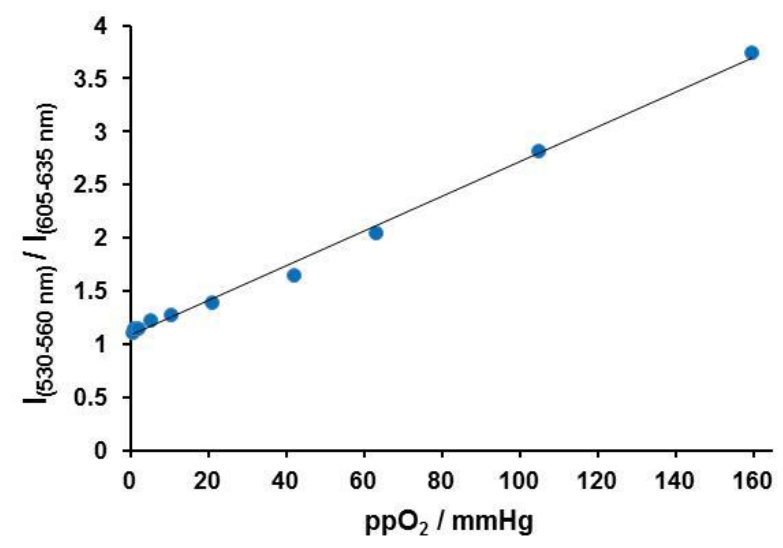

Figure 10. Variation of the ratio of the terbium emission intensity $\left(\lambda_{\text {exc }} 308 \mathrm{~nm}, \lambda_{\text {em }} 530-560 \mathrm{~nm}\right)$ for [TbLpp $\left.{ }^{j}\right]$ versus Eu emission in [EuLpp $\left.{ }^{j}\right]$, as a function of the partial pressure of oxygen in aqueous solution (295K).

\section{Summary and Conclusions}

In this work, we have developed a modular and flexible synthetic route to a family of ligands based on triazacyclononane that enables control of ligand and complex absorbance, in the range 330 to 360 
$\mathrm{nm}$, by variation of the substituents in the aryl ring or by changing the nature of the donor anionic group, exemplified by the behaviour of carboxylate and phosphinate groups. The phosphinate substitutents are shown via DFT and X-ray studies to present a steric shield that protects the lower face of the lanthanide complexes, enhancing their resistance to collisionally activated quenching processes and leading to longer excited state lifetimes.

The europium complexes possess both high emission quantum yields and high absorbance leading to several examples in which the brightness, $B$, is of the order of 15 to $30 \mathrm{mM}^{-1} \mathrm{~cm}^{-1}$, the highest reported for Eu complexes in solution. A direct consequence of this high brightness is to permit applications in immunoassays and in single-photon microscopy and spectral imaging that are otherwise limited to longer acquisition time or higher complex concentrations, for example enabling live cell imaging at low incident powers. Furthermore, the chromophore two-photon cross sections lie in the range 30 to $50 \mathrm{GM}$, sufficient to allow excitation between 700 and $720 \mathrm{~nm}$, as needed for two-photon microscopy studies. These studies, in concert with applications to near-IR emitting systems, will be discussed in forthcoming work.

The mechanism of sensitisation involves a relaxed ICT excited state or a ligand triplet intermediate according to the nature of the aryl substituents and the donor group. Very efficient intramolecular energy transfer occurs with the Eu(III) complexes, whereas for the $\mathrm{Tb}(\mathrm{III})$ analogues, back energy transfer occurs rapidly in all cases, due to the broad density of states or the relatively low energy of the triplet or relaxed ICT excited state and their closeness to the terbium ${ }^{5} \mathrm{D}_{4}$ emissive state. Using a mixture of $\mathrm{Tb}$ and $\mathrm{Eu}$ complexes of a common ligand, the ability to measure pO2 in solution was demonstrated.

\section{Experimental section}

Computational details. DFT geometry optimizations of the Y(III) complexes were carried out with the Gaussian 09 (revision A.02) package [28] employing the PBEO hybrid functional.[29] The "Stuttgart/Dresden" basis sets and effective core potentials were used to describe the yttrium atom,[30] whereas all other atoms were described with the SVP basis sets.[31]

\section{Optical measurements.}

Absorption spectroscopy UV/Vis absorption measurements were recorded using a JASCO V670 or a Perkin-Elmer Lambda 900 absorption spectrophotometer, using matched quartz cells.

Luminescence. Emission spectra were measured using a Horiba-Jobin Yvon Fluorolog- $3^{\circledR}$ spectrofluorimeter. The steady-state luminescence was excited by unpolarized light from a $450 \mathrm{~W}$ xenon $\mathrm{CW}$ lamp and detected at an angle of $90^{\circ}$ for diluted solution measurements $(10 \mathrm{~mm}$ quartz cell) by a red-sensitive Hamamatsu R928 photomultiplier tube. Spectra were reference corrected for both the excitation source light intensity variation (lamp and grating) and the emission spectral response (detector and grating). Phosphorescence lifetimes ( $>30 \mu \mathrm{s}$ ) were obtained by pulsed excitation using a FL-1040 UP Xenon Lamp. Luminescence decay curves were fitted by least-squares analysis using Origin ${ }^{\circledR}$. Luminescence quantum yields $Q$ were measured in diluted water solution with an absorbance lower than 0.1 using the following equation $Q_{x} / Q_{r}=\left[A_{r}(\lambda) / A_{x}(\lambda)\right]\left[n_{x}{ }^{2} / n_{r}{ }^{2}\right]\left[D_{x} / D_{r}\right]$ were $A$ is the absorbance at the excitation wavelength $(\lambda), n$ the refractive index and $D$ the integrated luminescence intensity. " $r$ " and " $x$ " stand for reference and sample. Here, reference is quinine bisulfate in $1 \mathrm{~N}$ aqueous sulfuric acid solution ( $Q r=0.546)$. Excitation of reference and sample compounds was performed at the same wavelength.

Two-photon excited luminescence measurements. The TPA cross-section spectrum was obtained by up-conversion luminescence using a Ti:sapphire femtosecond laser in the range 700-900 $\mathrm{nm}$. The 
excitation beam ( $5 \mathrm{~mm}$ diameter) is focalized with a lens (focal length $10 \mathrm{~cm}$ ) at the middle of the 10$\mathrm{mm}$ cell. Emitted light was collected at $90^{\circ}$ and was focused into an optical fiber (diameter 600 am) connected to an Ocean Optics S2000 spectrometer. The incident beam intensity was adjusted to 50 $\mathrm{mW}$ in order to ensure an intensity-squared dependence of the luminescence over the whole spectral range. The detector integration time was fixed to 1s. Calibration of the spectra was performed by comparison with the published 700-900 nm Coumarin-307 two-photon absorption spectrum 30 (quantum yield $=0.56$ in ethanol).[32]The measurements were done at room temperature in dichloromethane and at a concentration of $10^{-4} \mathrm{M}$.

Variable $T$ and pressure experiments. Details of the experimental set-ups used in the VT and VP experiments have been reported earlier. [27]

Confocal Microscopy. Details of cell culture, epifluorescence microscopy and assessment of complex toxicity, typically using the MTT assay of mitochondrial redox function have been reported elsewhere.[16] Cell images and co-localisation experiments were obtained using a Leica SP5 II microscope. In order to achieve excitation with maximal probe emission, the microscope was coupled by an optical fibre to a Coherent $355 \mathrm{~nm}$ CW (Nd:YAG) laser, operating at between 4 and $8 \mathrm{~mW}$ power. A HeNe or Ar ion laser was used when commercially available organelle-specific stains (e.g. MitotrackerGreen ${ }^{\mathrm{TM}}$ ) were used to corroborate cellular compartmentalization. The microscope was equipped with a triple channel imaging detector, comprising two conventional PMT systems and a HyD hybrid avalanche photodiode detector. The latter part of the detection system, when operated in the BrightRed mode, is capable of improving imaging sensitivity above $550 \mathrm{~nm}$ by $25 \%$, reducing signal to noise by a factor of 5 . The pinhole was always determined by the Airy disc size, calculated from the objective in use (HCX PL APO 63x/1.40 NA LbdBlue), using the lowest excitation wavelength (355 nm). Scanning speed was adjusted to $100 \mathrm{~Hz}$ in a unidirectional mode, to ensure both sufficient light exposure and enough time to collect the emitted light from the lanthanide based optical probes (1024x1024 frame size, a pixel size of $120 \times 120 \mathrm{~nm}$ and depth of $0.772 \mu \mathrm{m}$ ).

\section{Synthesis}

Details of general methods and of NMR and MS instrumentation may be traced in recent references. $[16,2,4,7,8]$. Experimental details of chromophore, ligand and complex syntheses are given in the ESI.

\section{Acknowledgements}

We thank EPSRC, the Royal Society and the ERC for support (DP, RP, SJB: FCC 266804); V.P. thanks the Lyon Science Transfer agency for financial support.

\section{References and notes}

[1] S. V. Eliseeva, J.-C. G. Bünzli, in Chap 1 Springer series on fluorescence, Vol. 7, Lanthanide spectroscopy, Materials, and Bio-applications, ed. P; Hännen and H. Härmä, Springer Verlag, Berlin, Vol. 7, 2010. S.V. Eliseeva, J.-C.G. Bünzli, Chem. Soc. Rev., 2010, 39, 189-227. R. Carr, N. H. Evans, D. Parker, Chem. Soc. Rev. 2012, 41, 7673-7686; A. D’Aléo, L. Ouahab, C. Andraud, F. Pointillart, M. O. Maury, Coord. Chem Rev. 2012, 256, 1604-1620.

[2] a) C. P. Montgomery, B. S. Murray, E. J. New, R. Pal, D. Parker, Acc. Chem. Res. 2009, 42, 925; b) E. G. Moore, A. P. S. Samuel, K. N. Raymond, Acc. Chem. Res. 2009, 42, 542; c) S. V. Eliseeva, J.-C. G. Bünzli, Chem. Soc. Rev. 2010, 39, 189. C. P. Montgomery, B. S. Murray, E. J. New, R. Pal, D. Parker, Acc. Chem. Res. 2009, 42, 925; d) M. C. Heffern, L. M. Matosziuk and T. J. Meade, Chem. Rev., 2014, dx.doi.org/10.1021/cr400477t.

[3] S. Faulkner, S. J. A. Pope, B. P. Burton-Pye, Appl. Spectro. Rev. 2005, 40, 1, E. J New, D. Parker, D. G Smith, J. W Walton Curr. Opin. Chem. Biol. 2010, 14, 238-246. 
[4] a) A. Picot, A. D'Aléo, P. L. Baldeck, A. Grichine, A. Duperray, C. Andraud, O. Maury, J. Am. Chem. Soc. 2008, 130, 1532; b) G.-L. Law, K.-L. Wong, C. W.-Y. Man, W.-T. Wong, S.-W. Tsao, M. H.-W. Lam, P. K.-S. Lam, J. Am. Chem. Soc. 2008, 130, 3714; c) F. Kielar, A. Congreve, G.-I. Law, E. J. New, D. Parker, K.-L. Wong, P. Castreno, J. de Mendoza, Chem. Commun. 2008, 2435; d) C. Andraud, O. Maury, Eur. J. Inorg. Chem. 2009, 2009, 4357.

[5] a) S. Pandya, J. Yu, D. Parker, Dalton Trans. 2006, 2757; b) S. Mizukami, K. Tonai, M. Kaneko, K. Kikuchi J. Am. Chem. Soc. 2008, 130, 14376-14377, c) C. M. G. dos Santos, A. J. Harte, S. J. Quinn, T. Gunnlaugsson Coord. Chem. Rev. 2008, 252, 2512-2527

[6] a) F. Degorce, A. Card, S. Soh, E. Trinquet, G. P. Knapik, B. Xie. Curr. Chem. Genomics 2009, 3, 2232, b) P. Scholler, J.M. Zwier, E. Trinquet, P. Rondard, J.-P. Pin, L. Prézeau, J. Kniazeff. Prog. Mol. Biol. Transl. Sci. 2013, 113, 275-312, c) J.M. Zwier, H. Bazin, L. Lamarque, G. Mathis. Inorg. Chem. 2014, $53,1854-1866$.

[7] a) G. Marriot, R.M. Clegg, D.J. Arnt-Jovin, T. Jovin, Biophys. J. 1991, 60, 1374-1387; b) A. Beeby, S.W. Botchway, I.M. Clarkson, S. Faulkner, A.W. Parker, D. Parker, J.A.G. Williams, J. Photochem. Photobiol. B 2000, 57, 83-89; c) V. Fernandez-Moreira, B. Song, V. Sivagnanam, A.-S. Chauvin, C. D. B. Vandevyver, M. A. M. Gijs, I. A. Hemmilä, H.-A. Lehrand, J.-C. G. Bünzli Analyst, 2010, 135, 42. d) H.E. Rajapakse, N. Gahlaut, S. Mohandessi, D. Yu, J.R. Turner, L.W. Miller, Proc. Natl. Acad. Sci. U.S.A., 2010, 107, 13582-13587

[8] M. Latva, H. Takalo, V.-M. Mukkala, C. Matachescu, J.C. Rodriguez-Ubis, J. Kankare, J. Lumin., 1997, 75, 149-169.

[9] a) B. Alpha, J.-M. Lehn, G. Mathis, Angew. Chem. Int. Ed. 1987, 26, 266; b) S. Petoud, S. M. Cohen, J.-C. G. Bünzli, K. N. Raymond, J. Am. Chem. Soc. 2003, 125, 13324. c) A. Bourdolle, M. Allali, J.-C. Mulatier, B. Le Guennic, J. M. Zwier, P. L. Baldeck, J.-C. G. Bünzli, C. Andraud, L. Lamarque, O. Maury, Inorg. Chem. 2011, 50, 4987.

[10] a) E. Deiters, B., Song, A.-S. Chauvin, C. D. B. Vandevyver, F. Gumy, J.-C. G. Bünzli Chem. Eur. J. 2009, 15, 885-900 ; b) S. V. Eliseeva, G. Auböck, F. van Mourik, A. Cannizzo, B. Song, E. Deiters, A.-S. Chauvin, M. Chergui, J.-C. G. Bünzli, J. Phys. Chem. B 2010, 114, 2932.

[11] a) V.-M. Mukkala, C. Sund, M. Kwiatkowski, P. Pasanen, M. Högberg, J. Kankare, H. Takalo, Helv. Chim. Acta 1992, 75, 1621; b) G. Piszczek, B.P. Maliwal, I. Gryczynski, J. Dattelbaum, J.R. Lakowicz, J. Fluo., 2001, 11, 101-107 ; c) P. Kadjane, M. Starck, F. Camerel, D. Hill, N. Hildebrandt, R. Ziessel, L. J. Charbonnière, Inorg. Chem. 2009, 48, 4601. N. N. Katia, A. Lecointre, M. Regueiro-Figueroa, C. PlatasIglesias, L. J. Charbonnière, Inorg. Chem. 2011, 50, 1689; d) M. Starck, P. Kadjane, E. Bois, B. Darbouret, A. Incamps, R. Ziessel, L. J. Charbonnière, Chem. Eur. J., 2011, 17, 9164-9179.

[12] M. Li, P. R. Selvin, J. Am. Chem. Soc. 1995, 117, 8132, Y. Bretonnière, M.J. Cann, D. Parker, R. Slater, Org. Bio. Chem., 2004, 2, 1624-1632.

[13] a) H. Takalo, I. Hemmilä, T. Sutela, M. Latva Helv. Chim. Acta 1996, 79, 789; b) C. Gateau, M. Mazzanti, J. Pecaut, F. A. Dunand, L. Helm, Dalton Trans. 2003, 2428; c) G. Nocton, A. Nonat, C. Gateau, M. Mazzanti, Helv. Chem. Acta 2009, 92, 2257.

[14] a) J. W. Walton, L. Di Bari, D. Parker, G. Pescitelli, H. Puschmann, D. S. Yufit, Chem. Commun. 2011, 47, 12289; (d) J. W. Walton, R. Carr, N. H. Evans, A. M. Funk, A. M. Kenwright, D. Parker, D. S. Yufit, M. Botta, S. De Pinto, K-L. Wong, Inorg. Chem. 2012, 51, 8042.

[15] A. D’Aléo, A. Bourdolle, S. Bulstein, T. Fauquier, A. Grichine, A. Duperray, P. L. Baldeck, C. Andraud, S. Brasselet, O. Maury Angew. Chem. In. Ed. 2012, 51, 6622 -6625.

[16] a) J. W. Walton, A. Bourdolle, S. J. Butler, M. Soulie, M. Delbianco, B. K. McMahon, R. Pal, H. Puschmann, J. M. Zwier, L. Lamarque, O. Maury, C. Andraud and D. Parker, Chem.Commun., 2013, 49, 1600-1602; b) L. Lamarque, O. Maury, D. Parker, J. Zwier, J. W. Walton, A. Bourdolle, PCT Int. Appl. (2013), WO 2013011236 A1 20130124; c) V. Placide, D. Pitrat, A. Grichine, A. Duperray, C. Andraud, O. Maury Tetrahedron Lett. 2014, 55 1357-1361; d) A. J. Palmer, S. H. Ford, S. J. Butler, T. J. Hawkins, P. J. Hussey, R. Pal, J. W. Walton, D. Parker RCS Adv. 2014, 4, 9356-9366; e) S. J. Butler, L. Lamarque, R. Pal, D. Parker Chem. Sci. 2014, DOI: 10.1039/c3sc53056f. 
[17] a) A. Picot, F. Malvolti, B. Le Guennic, P.L. Baldeck, J.A.G. Williams, C. Andraud, O. Maury Inorg. Chem., 2007, 46, 2659-2665; b) A. D’Aléo, A. Picot, A. Beeby, J.A. G. Williams, B. Le Guennic, C. Andraud, O. Maury Inorg. Chem., 2008, 47, 10258-10268.

[18] a) S. J. Butler, B. K., McMahon, R. Pal, D. Parker, J. W. Walton, Chem. Eur. J., 2013, 19, 95119517; b) B. K. McMahon, R. Pal, D. Parker, Chem. Commun., 2013, 49, 5363-5365.

[19] a) K. Sénéchal-David, A. Hemeryck, N. Tancrez, L. Toupet, J.A.G. Williams, I. Ledoux, J. Zyss, A. Boucekkine, J.-P. Guégan, H. Le Bozec, O. Maury J. Am. Chem. Soc., 2006, 128, 12243-12255; b) F. Pointillart, B. Le Guennic, O. Maury, S. Golhen, O. Cador, L. Ouahab Inorg. Chem., 2013, 52, 13981408.

[20] M. H. V. Werts, R. T. F. Jukes, J. W. Verhoeven, Phys. Chem. Chem. Phys., 2002, 4, 1542.

[21] A. Beeby, L. M. Bushby, D. Maffeo, J. A. G. Williams, J. Chem. Soc. Dalton Trans 2002, 48-54.

[22] T. Gallavardin, M. Maurin, S. Marotte, T. Simon, A.-M. Gabudean, Y. Bretonnière, M. Lindgren, F. Lerouge, P. L. Baldeck, O. Stéphan, Y. Leverrier, J. Marvel, S. Parola, , O. Maury, C. Andraud Photochem. \& Photobiol. Science 2011, 10, 1216-1225.

[23] A. Picot, A. D’Aléo, P.L. Baldeck, C. Andraud, O. Maury Inorg. Chem., 2008, 47, 10269-10279.

[24] Biphotonic cell imaging studies will be reported elsewhere. The resulting images are qualitatively identical under one or two photon excitation.

[25] E. J. New, A. Congreve, D. Parker, Chem Sci, 2010, 1, 111.

[26] B. Wang, Y. Liang, H. Dong, T. Tan, B. Zhan, J. Cheng, K. K-W. Lo, Y. W. Lam, S. H. Cheng, ChemBioChem, 2012, 13, 2729-2737

[27] a) G-L Law, R. Pal, L-O. Palsson, D. Parker, K-L. Wong Chem. Commun, 2009, 7321-7323 ; b) J. A. G. Williams, D. Parker, P. K. Senanayake, J. Chem. Soc. Perkin Trans. 2, 1998, 2129.

[28] M.J. Frisch, G. W. Trucks, H. B. Schlegel, G. E. Scuseria, M. A. Robb, J. R. Cheeseman, G. Scalmani, V. Barone, B. Mennucci, G. A. Petersson, H. Nakatsuji, M. Caricato, X. Li, H. P. Hratchian, A. F. Izmaylov, J. Bloino, G. Zheng, J. L. Sonnenberg, M. Hada, M. Ehara, K. Toyota, R. Fukuda, J. Hasegawa, M. Ishida, T. Nakajima, Y. Honda, O. Kitao, H. Nakai, T. Vreven, J. A. Montgomery, Jr., J. E. Peralta, F. Ogliaro, M. Bearpark, J. J. Heyd, E. Brothers, K. N. Kudin, V. N. Staroverov, R. Kobayashi, J. Normand, K. Raghavachari, A. Rendell, J. C. Burant, S. S. Iyengar, J. Tomasi, M. Cossi, N. Rega, J. M. Millam, M.; Klene, J. E. Knox, J. B. Cross, V. Bakken, C. Adamo, J. Jaramillo, R. Gomperts, R. E. Stratmann, O. Yazyev, A. J. Austin, R. Cammi, C. Pomelli, J. W. Ochterski, R. L. Martin, K. Morokuma, V. G. Zakrzewski, G. A. Voth, P. Salvador, J. J. Dannenberg, S. Dapprich, A. D. Daniels, O. Farkas, J. B. Foresman, J. V. Ortiz, J. Cioslowski, D. J. Fox Gaussian 09 Revision A.02, Gaussian Inc., Wallingford CT, 2009.

[29] a) C. Adamo, V. Barone, J. Chem. Phys., 1999, 110, 6158-6170; b) M. Ernzerhof, G. E. Scuseria, J. Chem. Phys., 1999, 110, 5029.

[30] M. Dolg, H.Stoll, H.Preuss, Theor. Chem. Acc. 1993, 85, 441.

[31] F. Weigend, R. Ahlrichs, Phys. Chem. Chem. Phys., 2005, 7, 3297.

[32] C. Xu, W. W. Webb, J. Opt. Soc. Am. B 1996, 13, 481-491. 